\title{
The Development of Students Geometrical Thinking through Transformational Processes and Interaction Techniques in a Dynamic Geometry Environment
}

\author{
Stavroula Patsiomitou \\ Department of Primary Education, \\ University of Ioannina, Greece
}

\author{
spatsiomitou@sch.gr
}

\begin{abstract}
The paper draws on a didactic experiment conducted in a secondary school mathematics classroom in Greece which aimed to explore a) ways in which students develop problem representations, reasoning and problem-solving, making decisions and receiving feedback about their ideas and strategies in a DGS-supported environment $b$ ) ways in which students develop rigourous proof through building linking visual active representations and c) ways to develop students' van Hiele level. The mathematical problem the students engaged with - either in the Geometer's Sketchpad dynamic geometry enviroment (Jackiw, 1988) or in the static environment - generated potentially insightful data on the issues focused on the comparison between the experimental and control groups. Initially, three pairs from the experimental group explored the treasure problem within a dynamic geometry environment. The discussions and results of the discussion were videotaped. The problem was then reformulated by the researcher taking into account the research group's retroaction, and re-explored by both the control and experimental groups in a paperpencil test. The researcher then (semi) pre-designed multiple-page sketches detailing the sequential phases of the solution to the problem using rigorous proof, and in so doing transferring her classroom reaching style into the software design, drawing on the chain questioning method of Socrates, which aim to stimulate interaction. For this reason, she linked all the software functions/actions using the interaction techniques supported /facilitated by the Geometer's Sketchpad v4 (DGS) environment (Jackiw, 1988) to better allow students to discover solution paths and to reason by rigorous proof. This mode of design and the results of the experimental use of the software with students led to the need to define two new concepts: the meanings of Linking Visual Active Representations (LVAR) and Reflective Visual Reaction (RVR). The researcher observed the students' actions and thinking processes during the research process and offers a description and analysis of these processes. An analysis of the results of the experimental procedure revealed

Material published as part of this publication, either on-line or in print, is copyrighted by the Informing Science Institute. Permission to make digital or paper copy of part or all of these works for personal or classroom use is granted without fee provided that the copies are not made or distributed for profit or commercial advantage AND that copies 1) bear this notice in full and 2) give the full citation on the first page. It is permissible to abstract these works so long as credit is given. To copy in all other cases or to republish or to post on a server or to redistribute to lists requires specific permission and payment of a fee. Contact Publisher@InformingScience.org to request redistribution permission.

that students are led to a) develop strategies for solving problems using the software, b) develop mental schemes through the construction of utilization schemes, c) improve their RVR through building/designing the activities as LVAR, d) develop their van Hiele level of geometrical thinking through the combining of the LVAR in the activities with the questions asked during the software procedure. The students' RVR
\end{abstract}


and van Hiele levels are used as descriptors for the dialogues' analysis.

Keywords: DGS, van Hiele model, mental schemes, Linking Visual Active Representations, Reflective Visual Reaction, rigourous proof

\section{Introduction}

Applying Comenius' rationale that "learning has been becoming more and more an activity", Freudenthal (1971, p. 415) adds that he dismisses the question "whether people learn better by active building up the subject than by passive reception of a ready made matter." This idea accords with the constructivist hypothesis as Mariotti (2002) declares "that learning results from a process of active adaptation of the learner to his /her environment, rather than a passive reception of information or instruction". On the other hand Nardi (1996, p.35) writes that "it is not possible to fully understand how people learn or work, if the unit of study is the unaided individual with no access to other people or to artefacts for accomplishing the task at hand". From this perspective, we consider the computer to constitute a fundamental artefact with a crucial role to play in learning processes. Computers, according to Pea (1985, p.167), are "reorganizers of mental functioning". The technological environment of the computer provides cognitive tools through which the user's communicative expression can be improved. Papert (1980) writes that children need tools to think with; a fundamental question concerns the ways in, and procedures through, which computers could be used effectively in education as cognitive tools to promote and reinforce cognitive processes, and act catalytically upon the quality of knowledge. According to Roschelle, Pea, Hoadley, Gordin, \& Means (2000, p.79), research into cognitive processes has shown that learning is most effective when four core conditions hold: (1) active engagement, (2) participation in groups, (3) frequent interaction and feedback, and (4) connections to real world contexts"; all supported through effective uses of technology.

Dynamic geometry systems have been described as computational environments that embody some subdomain of mathematics or science, generally using linked symbolic and graphical representations. Through computers' enviroment and dynamic geometry environments especially can allow students to explore the various solution paths individually and in small groups in which they make decisions and receive feedback on their ideas and strategies.

Mental schemes are developed by the students during problematic situations. Cobb, Yackel, and Wood (1992, p.4) suggest that "students construct mental representations that correctly or accurately mirror mathematical relationships located outside the mind in instructional representations".

Consequently: Which is the role of the computer in students constructing mental schemes? How can the computer contribute to the configuration of cognitive units, and thus operate as a reference point for organizing, pursuing, and retrieving information, and thus facilitating the reusing and handling of the schemes in a wide range of situations? How can the construction of rigorous proofs be affected by dynamic geometry systems? What impact can dynamic geometry systems have a student's van Hiele level?

Introducing new representational infrastructures (Kaput, Noss, \& Hoyles, 2002, p.2) such as dynamic geometry systems in the teaching and learning process makes it necessary to investigate the way in which students create mathematics and support reasoning. The focal point of interest, and subject under analysis, are the students' answers and the way in which they represent and verbally formulate concrete and abstract situations in problems. The present study a) focuses on the insightful data provided by a comparison of the experimental and control groups during the research process b) reports and describes a study undertaken to investigate the benefits of using (semi) pre-designed sketches relating to rigorous proof at the secondary school level; van Hiele levels are used as descriptor for the analysis. 


\section{The Role of the Dynamic Geometry Enviroment in Problem Posing}

Writing in "Crossroads in mathematics: Standards for introductory college mathematics before calculus" Daniel Alexander offers the following reflections on the value of students learning geometry (quoted in Larew, 1999): "Geometry is a vehicle that provides much of the basic core of knowledge that the student of mathematics should possess...introduction to forms of argument, introduction to forms of proof, the deductive skills that reach far away places ..." (in Cohen, 1995, p. 27). If we take the role of teacher seriously as concerns the realisation and planning of activities then, "every activity should be based on geometry" exactly as Goldenberg (1999) purports it to be -a fundamental principle.

Dynamic geometry systems such as the Geometer's Sketchpad (Jackiw, 1988) or Cabri II (J-M. Laborde, Baulac, \& Bellemain, 1988), or any other DGS software are microworlds which (Straesser, 2002, p.65) "even if the programs differ in their conceptual and ergonomic design, they share: a) a dynamic model of Euclidean school Geometry and its tools (the dragmode); b) the ability to group a sequence of construction commands into a new command (macroconstructions); c) the visualisation of the trace of points which move depending on the movement of other points (locus of points)". They were designed to facilitate the teaching and learning of Euclidean geometry and can play a fruitful and crucial role in the process of creating and evaluating conjectures which promote student creativity, and in so doing greatly contribute to developing mathematical reasoning. Geometer's Sketchpad v4 (or GSP) (Jackiw, 1988) is a dynamic geometry system and a tool for teaching mathematics, particularly high school geometry (e.g for explorations of geometrical constructions). The software's options menu, allow the user to produce constructions which must conform with the principles of Euclidean geometry if they are to function and pass the dragging test. This means that the student has to know the theory of geometry if $\mathrm{s} / \mathrm{he}$ is to make a correct geometric construction. Jones (2000, p.56) points out that "dynamic geometry systems (DGS) would seem to have the potential to provide students with direct experience of geometrical theory, and thereby break down what can be an unfortunate separation between geometrical construction and deduction".

By way of a brief overview, many researchers have conducted studies and concluded that students who used the Sketchpad displayed:

- more positive reactions when testing conjectures and constructions (see, inter alia, Growman, 1996);

- achieved significantly higher scores on a test containing concepts (see, inter alia, Dixon, 1996, who concludes that students who were taught about the concepts of reflection and rotation in a GSP environment significantly outperformed their peers who had received traditional instruction in the content measures of these concepts);

- achieved significantly higher scores between the pre- and post-tests (see, inter alia, Yousef, 1997 and Almeqdadi, 2000).

Researchers around the world concur in the view that greater emphasis should be put on activities in software that actively involve students. Activities should therefore be designed to motivate students and encourage them to actively construct knowledge. Designing learning activities, and making them effective in its static and dynamic dimensions, is a complex pedagogical task that lies at the heart of teacher practices involving in-class design. The role of the designer of the activities in the DGS environment - taking the designer to be the teacher in his/her professional practice - is crucial as s/he can develop the connection of interaction techniques (Sedig \& Sumner, 2006) in the computer software by evolving mathematical problem-solving techniques. This commentary on the integrated mode of designing activities consequently highlights the trying out 
of ideas in practice as a means of increasing knowledge while simultaneously improving curricula, teaching and learning (Kemmis \& McTaggart, 1982).

\section{The Role of van Hiele Levels for the Construction of Proofs in a DGS Enviroment}

The role of teaching and learning mathematical proof has been investigated by numerous researchers all over the world, each of whom tackled the issue from a different perspective. According to Olivero (2002) the main issues being tackled across all studies are:

- "the definition of roles and functions of proof in different historical and institutional settings";

- "the function proof should have in mathematics and in school mathematics";

- "the relationship between different activities involved in proving";

- "the ways to support students in their approach to proving in the classroom"

Strands of this research includes the analysis of students' cognitive processes during the construction of proofs (see, inter alia, Duval, 1991; Harel \& Sowder, 1996) and the teacher's role in the proof process (see, inter alia, Bartolini Bussi \& Mariotti, 1998). Other researchers have focused on the impact computer technologies can have in class with regard to proof (see, inter alia, C. Laborde, 1993; Schwartz \& Yerushalmy, 1992) some opting for a quantitative investigation of the impact dynamic geometry software can have on the process of proof (see, inter alia, de Villiers, 1998; Goldenberg, 1995; Olivero, 1999).

Olivero (2002) reports that "in some countries proof has been reduced in importance or eliminated from the mathematics curriculum" (Hanna, 2000, quoted in Olivero, 2002) but "in other countries, proof has been largely reintroduced in the curriculum since elementary school levels" [see, inter alia, the NCTM Standard 2000, http://standards.nctm.org quoted in Olivero, 2002).

The dynamic geometry software covered in this paper focuses on a) strategy development and the construction of meanings in student pairs in the DGS environment, and b) the orchestration of a "scenario in use" during the didactic experiment to better allow students to discover solution paths and to reason by rigorous proof (Patsiomitou \& Koleza, in press). The researcher carried out "the didactic experiment (in order) to raise students' thought levels" as Hoffer (1983, p.207) writes highlighting the endeavour of Dina Van Hiele-Geldof who enhanced students' thinking.

Dina van Hiele Hiele-Geldof (in Fuys, Geddes, \& Tischler, 1984, p.13) declares that "a didactic experiment involves the observation of psycological phenomena, the subjective attidute of the observer (something) that is almost impossimble to eliminate". According to Dina van Hiele Hiele-Geldof (in Fuys et al., p.16) the didactic experiments that she discussed had the objective "to investigate the improvement of learning performance by a change in the learning method ( underlined by the author)". She investigated in her study if "it was possible to use didactics as a way of presenting material, so that the visual thinking of a child is developed into abstract thinking in a continous process, something that is requisite for logical thinking in geometry". The materials used by Dina van Hiele to assist her students' progression though levels, were artefacts used to model or represent mathematical processes of concepts (made out of materials constructed by man).

Artefacts they can either be palpable (a card construction, for example) or digital (a software construction). The representation of mathematical objects using static means (e.g cardbord) is a timeconsuming process, and is not recommended in class, at least with High School students. On the other hand, students are drawn into a process when they can see it develop effectively and in real 
time in the environment in which they are working. Computers and specifically dynamic geometry systems are a part of the enviroment.

Fuys, Geddes, and Tischler (1988 quoted in Gawlick, 2005) support that "dynamic manipulations help students to transit from the first to the second van Hiele level". The level 3 (deduction) is identified "as the level which the students construct proofs, understand the role of axioms and definitions, and know the meaning of necessary and sufficient conditions" (Gawlick, 2005). Battista (1998 quoted in Gawlick, 2005) for example has developed a sequence of activities in a microworld to "encourage students to pass through the first three van Hiele levels."Gawlick (2005, p. 362) reports in his study, that he has developed "teaching materials that address level 3 (and higher) in a slightly different way than traditionally" and suggests that "progression through these levels will not occur all by itself, but needs to be triggered by giving the students suitable tasks that really afford the building of new concepts".

Meaning that those activities that contribute to the active, discovery-based teaching method is an artefact, and the logic underlying their design is of concern to Maths teachers who seek to teach their subject in class using material which makes it easier for students ascend to a higher level. The researcher expended a great deal of thought on designing activities which transferred to the software environment the teaching methods she used in class using static means which resulted in her students' levels of thought rising slowly.

This was what drove her to construct in the dynamic geometry enviroment of the Geometer's Sketchpad, (semi) pre-designed multiple-page sketches of the problem described in the next section, in line with a specific logic via which the students' level of thought rose. This was the final stage in her four phase research method which will be described in due course.

\section{The Design of the Open Ended Problem in A DGS Enviroment}

Freudental (1971, p. 413) self responding to his own question about "What is mathematics" argues that: "mathematics is an activity.... which can be a matter from reality... which has to be organized according to mathematical patterns if problems from reality have to be solved."

The researcher chose a problem that would stimulate the students' interest and urge them to use their knowledge of geometry to: a) visualize and conjecture, b) investigate, and c) prove. According to Kilpatrick (1987) "Problem formulating should be viewed not only as a goal of instruction but also as a means of instruction."

A problem created by George Gamow (1948, reprinted 1988) involving pirates and buried treasure seemed ideal. The researcher bolstered the problem with historical evidence from Homer, seeking thus to motivate her pupils to develop their interest in ancient history through Maths. Gamow's problem hinges on a treasure map found in an old man's attic. Here is the revision provided by the researcher:

"In the Odyssey, Homer (c74-77) mentions that the pirates also raided Greek islands. The pirate in our story has buried his treasure on the Greek island of Thasos and noted its location on an old parchment. "You walk directly from the flag (point $F$ ) to the palm tree (point $P$ ), counting your paces as you walk. Then turn a quarter of a circle to the right and go to the same number of paces. When you reach the end, put a stick in the ground (point $K$ ). Return to the flag and walk directly to the oak tree (point $O$ ), again counting your paces and turning a quarter of a circle to the left and going the same number of paces. Put another stick in the ground (point L). The treasure is buried in the middle of the distance of the two sticks (point T)."(Figure 1) After some years the flag was destroyed and the treasure could not be found through the location of the flag (Figure 2). Can you find the treasure now or is it impossible?" 
Figures 1 and 2 are screenshots of the software. The proof usually involves complex numbers or algebra /geometry. The exploration in the following sections employs the Geometer Sketchpad v4 and a geometry framework as its medium of investigation and productive reasoning. As a consequence, the researcher using interaction techniques (Sedig \& Sumner, 2006) to design the problem in the software's multiple pages.

The interaction techniques used will be reported in full over the research along with their impact on the pupils' representation, problem solving and proof construction skills. The experimental stage will then include an explanation of the design approach using screenshots, and link the activity design process to students' reactions and the effect these techniques have on classroom interaction.

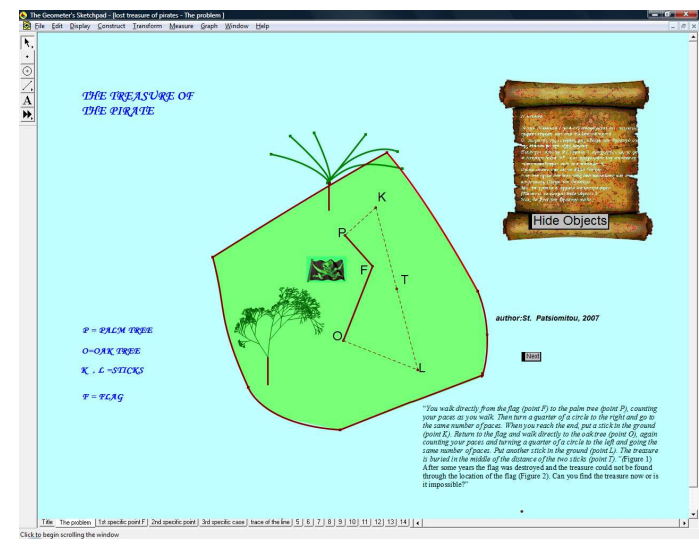

Figure 1: Screenshot from the software before hiding the flag

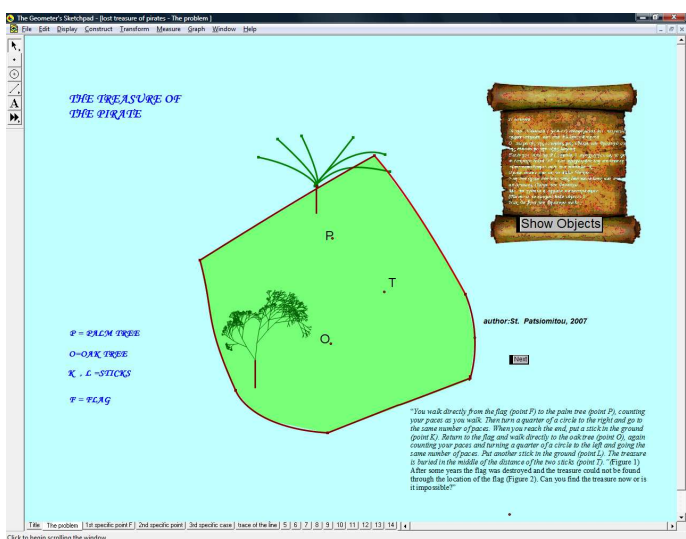

Figure 2: Screenshot from the software after hiding the flag

At this stage, we shall limit ourselves to mentioning two important factors the researcher took pains and a great deal of thought, to take into account when designing the activities, both of which are based on classroom observations made over many years of teaching geometrical proof.

Namely:

- linking the steps in the constructional, transformational or explorative actions or processes in the software using interaction techniques (Sedig \& Sumner, 2006)

- linking the steps in the proof via a sequence of pages or the same page in the DGS environment using interaction techniques (Sedig \& Sumner, 2006)

Both factors impact directly on how students are guided to the proof process through solving problems, and hence on how students are guided to abstract thought processes. Thus, during the problem-solving process or when reproducing a theorem with a view to proving it, the teacher or students ask questions which help them construct the proof. Thus, a problem would be solved by breaking it down into a series of questions whose answers gradually distil the proof the students seek. This process is reminiscent of the Socratic method ("maieftiki" in Greek) by which teachers ask questions designed to elicit the correct answer and reasoning processes. The questioning process thus helps students determine and extend their underlying knowledge. The researcher took this entire process of the Socratic method and transferred and adapted it for the software, which is to say she connected or foresaw the questions explicitly or implicitly posed by the teacher or students and linked the different stages in the proof to different pages in the software. During teaching sessions, the students had to reason at the same speed as the rapidly repeated questions asked by the researcher, who had to reason both more quickly and more correctly than 
the students, or discover errors in the students' reasoning and formulate questions the students could only answer through a process of reasoning.

In this way, neither teacher nor students waste time on constructing all the problem's reconstructive steps in class, since these can be revealed by clicking on an action button.

Here are two examples of half pre-designed steps to illustrate the software process: a) the straight section KL has been joined using trace, and the new position of point $F$ has produced a different trace of the straight section KL. This action corresponds to the question: "What would happen, do you think, if we changed the position of point F, where the flag is?" We then leave the students to answer by moving Point F. This produces a series of lines KL, all of which pass through Point T. "Trace" according to Jahn (2002) "emphasises a dynamic interpretation of the representation of a trajectory of a point ... representing, at least implicitly, the image of a set of points for a certain application." b) In Figure 2, a pre-designed hide/show action button allows the user to hide the flag and with it Point F, which allows students to experiment and investigate the subject in their own way. This action causes the lines which could lead to the treasure point $\mathrm{T}$ simultaneously disappearing. The researcher deliberately left Point $\mathrm{T}$ on the screen, because if it disappeared, the students would be unable to visualize or investigate the problem.

This means that the process is directly linked to how the activities can guide the students to reach conclusions. Bringing this analysis of the logic of the design process, it should be noted that the researcher bore the following in mind when designing, constructing and implementing the activities: a) the process should be active to keep the students interested and promote discovery; a) students should be guided to reach conclusions in the strict sense of a conclusion stemming from a Euclidean proof, c) the theories detailed in the next section which deal with knowledge, teaching and the learning of Mathematics.

This approach to design ensures that the teaching process provides the students with the guidance they require, and helps them replace their pre-existing / extant knowledge by assimilating new knowledge or accommodating it as complementary to what they already know (Piaget's assimilation and accommodation), or by confirming / anticipating the pupil's thought processes and mental approaches.

\section{Theoretical underpinning}

"After observing secondary school students having great difficulty learning geometry in their classes, Dutch educators Pierre van Hiele and his wife Dina van Hiele-Geldof developed a theoretical model involving five levels of thought development in geometry" (in Fuys et al., 1984, p.6) The model of van Hiele describes levels of thinking that students progress through in reasoning about geometry and focuses "on the role of instruction in teaching geometry and the role of instruction in helping students move from one level to the next" (in Fuys et al., 1984, p.6). The van Hiele theory distinguishes five different levels of thought. Fuys et al. specified that to be "on a level" students had to consistently exhibit behaviours indicative of that level. The usual interpretation and general features of the first four levels, which are most pertinent to secondary school geometry, can be described as follows (De Villiers 2004; Gawlick 2005):

- Level 1 (recognition or visualization): students visually recognize figures by their global appearance. The properties of the figure are not explicitly identified or perceived.

- Level 2 (analysis): students start analysing the properties of figures and learn the appropriate terminology for their description. They can recognize and name properties of geometric figures, but do not see relationships between these properties.

- Level 3 (ordering): students logically order figures' properties by short chains of deductions and understand the interrelationships between figures. 
- Level 4 (deduction): students start developing longer sequences of statements and begin to understand the significance of deduction, the role of axioms, theorems and proof.

Fuys et al. (1988 quoted in Gawlick, 2005) argue that dynamic manipulations help students move from the first to the second van Hiele level. Level 3 (deduction) is identified as the level which is connected with the construction of "if...then" statements, and consequently with proof (Gawlick 2005). Vygostky (1934, p.150) declares that: "the direct teaching of concepts is impossible and fruitless. A teacher who tries to do this usually accomplishes nothing but empty verbalism". The mediatory role of the activities in introducing geometrical meanings is fundamental. It would thus seem very important for geometry teachers to know their students' levels of geometric thought based on the van Hiele model and to develop/design activities accordingly. Pierre van Hiele in Fuys, et al. (1984, p.247) writes: "If we agree that the aim of our teaching is that the student should know how to prove theorems, it is highly improvable that the student's thought is aimed directly towards this goal".

Another important aspect of the van Hiele model is the five phases it specifies in the apprenticeship/learning process, which are, in brief (Fuys et al., 1984): 1) information (inquiry), 2) directed orientation, 3) explication, 4) free orientation, 5) integration. Instruction that takes this sequence into account promotes the acquisition of a higher level of thought. According to Freudenthal (1973, p.418 quoted in Gawlick, 2005) "Good geometry instruction can mean much - learning to organize a subject matter and learning what is organizing, learning to conceptualize and what is conceptualizing, learning to define and what is a definition. It means leading pupils to understand why some organization, some concept, some definition is better than another. Traditional instruction is different... All concepts, definitions and deductions are preconceived by the teacher."

In the software, the researcher chose a modern adaptation of the Socratic Method. The Socratic Method is a dialectic method of inquiry. Freudenthal (1971, p.414) supports that "Socrates did not teach a ready made solution but the way of reinventing the solution." The same approach two millenia later was formulated by Comenius (quoted in Freudenthal, 1971): "The best way to teach an activity is to show it." According to Freudenthal "this is a socratic idea, though it involves more than a Socratic lesson. While Socrates taught his lesson, the slave listened, whereas Comenius will show the student an activity to explain afterwards what it means and finally to have it imitated by the student." Freudenthal supports that modern educators are likely to subscribe to a variation of Comenius' device while "The best way to teach an activity, is (not) to show it" but rather "The best way to learn an activity, is to perform it."

The researcher opted to serve as a teacher at many stages during the research. Cobb and Steffe (1983) enhance the idea of the researcher as teacher supporting that "the activity of exploring children's construction of mathematical knowledge must involve teaching". According to them there are three important reasons for this:

- "the insufficiency of relying solely on a theoretical analysis"

- "the experiences children gain through interactions with adults greatly influence their construction of mathematical knowledge"

- "the importance we attribute to the context within which the child constructs mathematical knowledge"

The role of the teacher as mediator is crucial during the active process of teaching and learning mathematics while according to Mariotti (2002, p.16) "a semiotic mediation develops on different levels... and the construction of meanings occurs as the product of a process of internalisation guided by the teacher".

The activity theory which considers tool use to be embedded in social practice could provide a fruitful additional perspective. In the activity theory frame, the learning environment is consti- 
tuted by the enactment of a teaching/learning activity oriented to an educational object, involving student, teachers and artifacts. Bellamy (1996, p.123) asserts that activity theory is an appropriate framework for the analysis of innovations partaking of technology (such as the design of activities) because 'it is part of a general process of cultural evolution in which artefacts mediate human activity'. Kuutti (1996) states that the relationship between activities and information technology mediating education may involve:

- "automating and substituting human operations",

- " "serving as a tool in manipulative and transformative actions", and

- "helping in actions directed towards sense making".

Activity theory "can be used also to describe the system of relationships characterizing a teaching/learning activity" (Cerulli, Pedemonte, \& Robotti, 2005). A learning environment and especially a DGS learning enviroment is something which is co-built in the teaching and learning activity by participants of the activity. According to Cerulli, Pedemonte, \& Robotti (2005) "the teacher, which is a co-actor of the activity, can administrate/control/cause such changes, thus guiding the development of the activity according to his/her educational goal or to the exigencies of the class."

A part of the study that which is discussed "research using LVAR" is underpinned by the theory of the instrumental orchestrations. Instrumental orchestration is defined by Guin and Trouche (2002, p.208) as: a set of individuals; a set of objectives (related to the achievement of a type of task or the arrangement of a work-environment); a didactic configuration (that is to say a general structure of the plan of action); a set of exploitation modes of this configuration. "The necessity of orchestrations is apparent from this point of view, during the learning process of mathematical science considered as a construction of the 'web' between the categories of the problems, the mathematical objects and relations (Noss \& Hoyles 1996, p.105 quoted in Trouche, 2004)". During the third Computer Algebra in Mathematics Education (CAME) Symposium, the Mind \& Machine group ("Discussion session of the Mind \& Machine group," 2003) coordinated by Drijvers supported among others the following: "the notion of webbing was developed as a reaction to the notion of scaffolding. ... How about the role of the teacher? His/her role is not included in the notion of webbing. In orchestration it is. We should support the students in webbing, and orchestration might be one way."

Guin, Ruthven, and Trouche (2004, p. 300) point out that C. Laborde (1999) has developed usage scenarios for geometry software "for teachers wanting to produce teaching units.... with its objectives, student materials, and supporting notes for teachers to help put the unit into practic". Trouche (2004, p.303) writes that "an orchestration is part of a didactical exploitation scenario. A scenario in use gives elements (various stages of the activity, organization of study time and space) necessary for the teachers to conceive instrumental orchestrations in their classes (Trouche, p.2004)."

Artigue (2000), Guin and Trouche (1999), and Trouche (2004) describe the dual interactive process of instrumental genesis (Verillon \& Rabardel, 1995), which takes place in a class of students who share the same objective, distinguishing two distinct processes the 'instrumentation process' and the 'instrumentalization process'. Concretely Artigue (2000) writes that instrumental genesis is directed towards:

a) "the subject, and leads to the development or appropriation of schemes of instrumented action which progressively constitute into techniques which allow us to solve given tasks efficiently" (instrumentation process)

b) "the artefact, loading it progressively with potentialities, and eventually transforming it for specific uses" (instrumentalization process) 
From Trouche's point of view, "instrumental geneses are individual processes, developing inside and outside classrooms, but including of course social aspects" (see Figure 3 ) (personal e-mail correspondence with Professor Trouche on April 4, 2008). Trouche supports that "an artefact is tranformated thus through instrumental geneses, oriented by finalized actions, assisted by instrumental orchestrations, into an intrument".

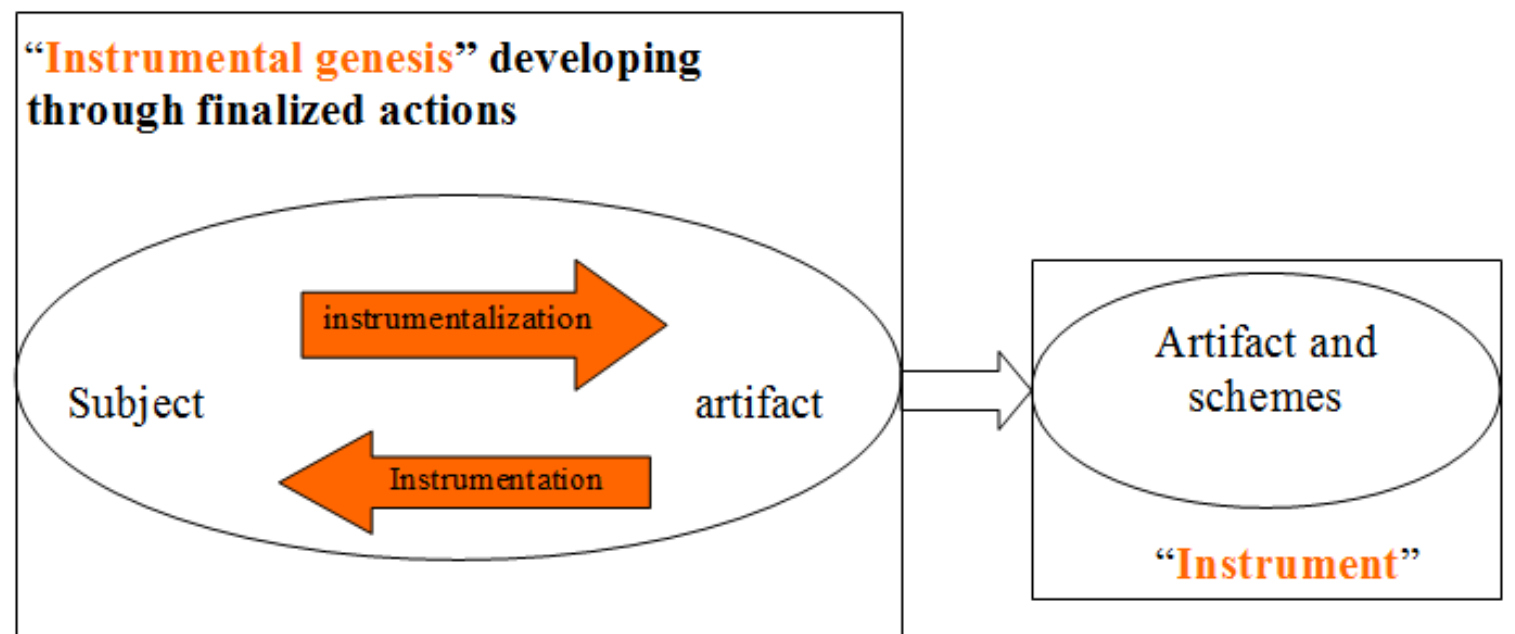

Figure 3: The schema of instrumental approach (personal e-mail correspondence with Professor Trouche on April 2, 2008) based on Trouche's (2006) schema of instrumental approach

According to Artigue (2000), "An instrument is thus seen as a mixed entity, constituted on the one hand of an artefact and, on the other hand, of the schemes that make it an instrument for a specific person. These schemes result from personal constructions but also from the appropriation of socially pre-existing schemes."

Rabardel (1995) calls the schemes linked to the utilization of an artifact utilization schemes According to Rabardel: "Usage schemes are "related to 'secondary tasks' corresponding to the specific actions and activities directly related to the artifact" and "Schemes of instrumented action are "related to 'primary tasks' aiming at operating transformations on the object of activity"

Through the instrumented action schemes, mathematical knowledge and knowledge of the tool are combined. As Trouche (2004, p. 286) notes: "A scheme has thus three main functions: a pragmatic function (it allows the agent to do something), a heuristic function (it allows the agent to anticipate and plan actions) and an epistemic function (it allows the agent to understand something)."

FitzSimons (2005) writes that "Trouche in his discussion of instrumental orchestration, exemplifies the three activity theory levels which are":

- the first level where "the focus is on the ordinary utilisation of the artefact, and students may be helped learn the mechanics of computing"

- the second level, where "artefacts as instruments correspond to both representations and action modes, in order to encourage debates and to make procedures explicit, or as a means to reintegrate remedial or weak students into the class"

- the third (or 'meta') level where "the artefacts offer reflective methods of self analysis of the activity, both individually and collectively"

As Trouche suggests "the development of a learning environment requires three levels of control: a topic oriented one (here mathematical); a technological one (to understand the constraints and 
the potential of artefacts), and a psychological one (to understand and manage the various processes of instrumental genesis for the learners and for the teachers). These three levels can be kept separate for analytical purposes, but they must be integrated for design purposes" (in the editorial of Waern, 2003, p.733).

In the next section, are defined the terms of LVAR and RVR, explaining what interactive techniques are, and how they can be applied to visual mathematical dynamic representations of the DGS environment with a view to analyzing the students' work and problem-solving strategies.

\section{The Design of the Activities using Linking Visual Active Representations (LVAR). The Role of Interaction Techniques to the Reflective Way of Thinking (RVR).}

Researchers around the world concur in the view that visualizations and links between mathematical representations are fundamental to understanding how students construct mathematical concepts and solve problems (see, inter alia Duval, 1993; Eisenberg \& Dreyfus, 1990; Janvier, 1987; Kaput, 1994; Presmeg, 1986; Vergnaud, 1987). Kaput et al. (2002) in their paper "Developing New Notations for a Learnable Mathematics in the Computational Era" analysed "the ways we use to present and re-present our thoughts to ourselves and to others, (in order) to create and communicate records across space and time, and to support reasoning and computation" (p. 2) namely "how in the evolution of the new representational infrastructures, and the associated artifacts and technologies have, over long periods of time, gradually externalized aspects of knowledge and transformational skill that previously existed only in the minds and practices" (p.33). As they declare "a key aspect of the...representational infrastructure is revealed when we compare how the knowledge and skill embodied in the system relates to the knowledge and skill embodied in the usual curriculum" wishing "to challenge our community to focus attention on the design and use of representational infrastructures that intimately link to students' personal experience."

The term "representation" and the expression "system of representation", in connection with mathematics teaching and learning, has the following interpretation given by the following quote of Goldin and Janvier (1998, p.1):

- An external, structured physical situation, or structured set of situations in the physical environment, that can be described mathematically or seen as embodying mathematical ideas;

- A linguistic embodiment, or a system of language, where a problem is posed or mathematics is discussed, with emphasis on syntactic and semantic structural characteristics;

- A formal mathematical construct, or a system of constructs, that can represent situations through symbols or through a system of symbols, usually obeying certain axioms or conforming to precise definitions--including mathematical constructs that may represent aspects of other mathematical constructs;

- An internal, individual cognitive configuration, or a complex system of such configurations, inferred from behavior or introspection, describing some aspects of the processes of mathematical thinking and problem solving.

Visual Mathematical Representations (VMRs) according to Sedig and Sumner (2006, p.2) are those representations that "encode these properties and relationships for a represented world consisting of mathematical structures or concepts (Cuoco \& Curcio, 2001; Hitt, 2002; quoted in Sedig \& Sumner, 2006) in providing a framework to help designers of mathematical cognitive tools in their selection and analysis of different interaction techniques as well as to foster the design of more innovative interactive mathematical tools" (Sedig \& Sumner, 2006). 
Sedig, Rowhani, \& Liang (2005, p.422) pinpoint that "the interaction with VMRs in a computing environment has two aspects: the action upon a representation by the user through the intermediary of a human-computer interface, and the representation communicating back through some form of reaction or response." Sedig, Klawe, and Westrom (2001 quoted in Sedig \& Sumner, 2006) conducted an empirical study and they found that "adding scaffolding to direct manipulation of representations of transformation geometry concepts significantly improved student learning"

Sedig and Sumner (2006) have distinguished between basic and task-based interactions with VMRs. To achieve pupil interaction using VMRs, the researcher used a diverse set of interaction techniques including "animating" a point on its path, "tracing" a segment, "hiding and showing" action buttons, and "linking" or "presenting" action buttons. In so doing, she successfully linked both the steps in constructional and transformational actions and the various sequential phases in the proof. According to Sedig and Sumner (2006) "Benefits of animating VMRs include: attracting and directing attention to embedded detail, visualizing dynamic and transitional processes, supporting external cognition, increasing visual explicitness of encoded information, and facilitating perception of semantic and temporal transformations inherent in the VMR". The rotation command /technique "has been referred to as direct concept manipulation, as opposed to direct object manipulation" (p.35) because "if students are to focus on the concept of rotation, rather than focusing on the shape being rotated, they can directly interact with a visual representation of rotation" (Sedig et al., 2001 quoted in Sedig \& Sumner, 2006). The linking of sequential phases in a proof or actions over multiple pages or evolving steps in the representation of the problem leads to a cognitive linking of the representations which (Kaput, 1989) "creates a whole that is more than the sum of its parts...It enables us to see complex ideas in a new way and apply them more effectively". As Mariotti (2002, p. 22) declares "the temporal sequence of the constructions' steps represents the counterpart of the logic hierarchy between the geometric properties of a figure". Figure 4 is a screenshot showing a pop-up menu, the rotate command and the transformation of a segment by rotating it through 90 degrees. Figure 5 is a screenshot showing the action buttons for hiding/showing objects on screen, a presentation button which repeats actions sequentially, and a link button which links the current page with the next one, thereby connecting the actions.

The teacher can guide the students by means of elucidation or questions eliciting conclusions which form a step-by-step visual proof. The software's successive pages also play a significant role, and can be seen as a vivid section in a book revealing the various stages in the proof. The sequence of increasingly sophisticated construction steps could thus correspond to the numbering of the action buttons which allows student to interact with the tool when they want to, or when they are encouraged to do so by their teacher in class.

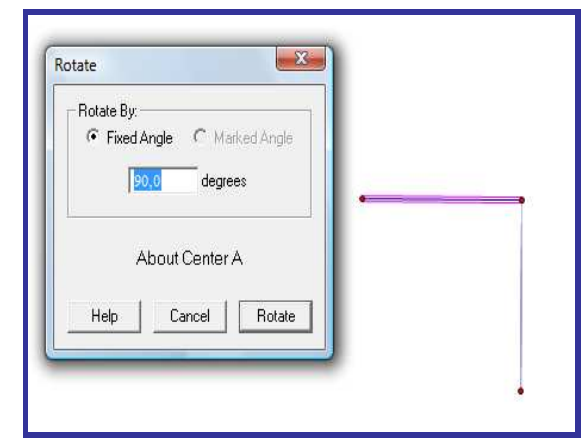

Figure 4: A screenshot showing a pop-up menu of the rotate command

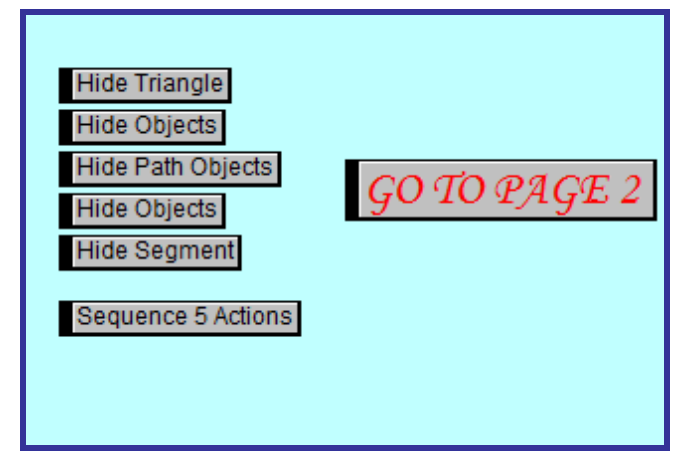

Figure 5: A screenshot showing the action buttons for hiding/showing objects on screen 
Building on the above-reviewed theoretical background and new views, the meanings of Linking Visual Active Representations, and Reflective Visual Reaction during a dynamic geometry problem solving session, recently introduced by Patsiomitou and Koleza (to appear), are complementarily re-defined in the present study directly connected with the design process in the software as follows:

Linking Visual Active Representations are the successive phases of the dynamic representations of the problem which link together the problem's constructional, transformated representational steps in order to reveal an ever increasing constructive complexity; since the representations build on what has come before, each one is more complex, and more integrated than in previous stages, due to the student's (or teacher's, in a half-preconstructed activity) choice of interaction techniques during the problem-solving process, aiming to externalize the transformational steps they have visualized mentally (or exist in their mind).

Reflective Visual Reaction is that reaction which is based on a reflective mode of thought, derived from interaction with LVAR in the software, thus complementing and adding to the student's pre-exesting knowledge or facilitating comprehension and integration of new mathematical meanings.

Through LVAR a connection between the "scenario in use" (Trouche, 2004) of the activity and "a learning scenario" (Lejeune \& Pernin, 2004) in a computing environment is being undertaken. In that case the ICT tool cooperates with the subjects (or serves as an environment promoting cooperation) "and is not antagonist to them as in the case of the milieu antagoniste described by Brousseau (1986)" (Cerulli, Pedemonte, \& Robotti, 2005). According to Patsiomitou and Koleza (in press), "The LVAR process is a continuous interplay among the teacher, the pupils and the artefacts /tools including the computer software. By this meaning we have a crucial mediation role of the instruments, the rules, and the division of labour in the three relationships characterizing the teaching /learning activity, that means characterizing the relationships between subject and object (for example between a pupil and the designed activity in the ICT tool), between subject and community (for example between the teacher and the whole class) and between the community and the object (for example between the whole class and the tool /artefact)."

\section{Research Methodology}

The qualitative study presented herein/in this paper was conducted in a secondary school Mathematics class in Athens, Greece, and sought to explore a) ways in which students in small groups develop problem representations, reasoning and problem-solving, making decisions and receiving feedback about their ideas and strategies in a DGS-supported environment b) ways in which students develop rigourous proof through building linking visual active representations and c) ways to develop students' van Hiele level. The didactic experiment was conducted in a class at a public high school in Athens during the second term of the academic year, and involved 65 students aged 15-16. Firstly the researcher examined student's level of geometric thought using the test developed by Usiskin (1982) at the University of Chicago which is in accordance to the van Hiele model using only the first 20 twenty questions of the questionaire. It came to light that there were students in transit between one level and another, which confirmed the view stated by other researchers (for example Fuys et al., 1988), who reported that students especially those in transition, are difficult to classify reliably, especially for levels 2 and 3. "For the research process twenty eight volunteers students were randomly divided between the 'experimental' and the 'control' teams, with 14 students in each. The researcher ensured that both teams consisted of equal number of: students at levels 1 to 3 respectively; boys and girls. The students were friends, which fostered group discussion. The experimental team had participated in 3 previous sequential 
phases consisting of instructional / interactional sessions with the geometry software before exploring the concrete problem" (Patsiomitou \& Koleza, in press).

Cooperation and peer interaction in small groups in a given problem-solving activity has been rendered a significant area of research in mathematics education (for example Kieran \& Dreyfus, 1998). Although in this type of interaction the students are given the opportunity for discourse and to exchange ideas and opinions, Kieran and Dreyfus focused on the difficulties which occurred "entering one another's universe of thought". It is also important to examine how students' extant knowledge affected the results of the research. On the other hand, Kaput (1998, p.7) claims "Just because representations are linked, if there is no connection to other knowledge in the learner's schema / experience the linked representations are just as meaningless. Students may cause and effect relationships within the representations yet still not have a mental image of what any of the representations linked or not mean."

The problem situation explored by the pupils was the revised version of the "lost treasure of the pirates" problem conceived by the Russian, George Gamow (1948, reprinted 1988), mentioned at the design of the problem section. Numerous researchers have been attracted to the problem (including De Villiers (1999) and Scher (2003), who designed the activity over multiple pages using interactive constructions) by using the Geometer's Sketchpad v4.

The problem struck the researcher as particularly interesting because it allows three quite different approaches: (i) the so-called 'static' approach; (ii) a software-supported: 'dynamic' approach; and (iii) a paper and pencil 'dynamic' approach concerning dynamic methods in geometry, consisting of 'thinking in motion' in a paper pencil environment.

The methodology of the class experiment discussed in this paper includes an exploration of the open problem. The students in the experimental team had to explore the problem using static or dynamic means, while the control group had to examine the problem using static means alone.

The researcher followed five steps for the inquiring process which are reported below:

Initially, two pairs of the experimental group explored the open-ended realistic problem within a dynamic geometry environment. The discussions were videotaped and examined simultaneously with the researchers' notes during the inquiring process. The section "Research in the Dynamic Geometry Enviroment" presents the pairs' sessions the students undertook in the dynamic geometry enviroment

The solution to the same problem was explored by the control group with static means and was discussed through a didactic session. The second part of the next section presents the didactical analysis.

Thereafter the problem was reformulated by the researcher taking into account the retroactions by the research group and was re-explored by the students of the control and experimental group through a paper-pencil test. The third part of the next section presents the research with static means and the comparison between the experimental and the control team.

The section "Research Using LVAR" presents:

a) One pair's session the students undertook using LVAR.

b) An orchestration with most students of the experimental team interplayed with LVAR to solve the problem with rigourous proof. The experimental sessions with LVAR were videotaped. The analysis of the results that follows is based on observations in class and of the video. The students' talk is in Italics. 


\section{Research Process (without using LVAR)}

\section{Research in the Dynamic Geometry Enviroment}

Research questions:

1. How important is pre-existing knowledge of the theorems to problem solving?

2. Does the DGS environment assist the students develop strategies in order to solve a problem after exploring it in a DGS environment?

3. Does the DGS environment assist the students construct meanings and mental schemes?

4. What conclusions can be drawn from the dialogues with regard to the students' level? Is the van Hiele level derived from the students' answers different from their level in the pre-test?

A presentation of the research relating to pairs of the experimental group follows who explored the open-ended realistic problem within the dynamic geometry environment. The discussions were videotaped and examined simultaneously with the researchers' notes during the inquiring process. Every dialogue is followed by a short analysis correlated with the research questions.

\section{Group A:}

Field note 1: Group A consists of students M1, M2. M1 is a male student (van Hiele level: 1) and M2 is a female student (van Hiele level: 2) at the pre-test about 4 months ago. They are medium achievers with respect to mathematics. The session described here lasted almost 15 minutes. As students experimented with the trace command, segment KL left a trace when point $F$ was dragged to any orientation manually using the mouse (or animation tool). As the students investigated the problem, they noted that the position of the treasure remained constant on the screen. The researcher urged students to hide the initial construction and make their own one from scratch following the instructions provided on the parchment. Alternatively, the students could react spontaneously using the mouse. They could also do guided dragging in order to make a decision that might lead to the solution.

201. $\mathrm{M}_{2}$ : To start with, we could join points $P$ and $O$ with a segment (Figure 6)

\begin{tabular}{|l|l|}
\hline Student $\mathrm{M}_{2}$ & Analysis of the student'verbal formulation \\
\hline $\begin{array}{l}\text { To start with, we could join points } P \text { and } \\
\text { O with a segment }\end{array}$ & $\begin{array}{l}\text { The pupil develops a strategy in order to } \\
\text { solve the problem }\end{array}$ \\
\hline
\end{tabular}

202. $M_{1}$ : Then we can, construct a point $F$ on the segment. Point $F$ does not affect the position of point $T$, as we have seen before using the trace command.

\begin{tabular}{|l|l|}
\hline Student $\mathrm{M}_{1}$ & Analysis of the student's verbal formulation \\
\hline $\begin{array}{l}\text { Then we can, construct a point } F \text { on the } \\
\text { segment }\end{array}$ & $\begin{array}{l}\text { The pupil finds a solution which implies the } \\
\text { use of the rotation command } \\
\text { which means that he has constructed a usage } \\
\text { scheme of the tool }\end{array}$ \\
\hline $\begin{array}{ll}\text { Point } F \text { does not affect the position of } \\
\text { point } T\end{array}$ & $\begin{array}{l}\text { He means for any point } \mathbf{F} \text { which expresses a } \\
\text { generalization }\end{array}$ \\
\hline
\end{tabular}


as we have seen before using the trace command a utilization scheme derived from the trace command (Tracing the segment impacts on pupils' knowledge )

Field note 2: $\mathrm{M}_{1}$ does not express his thoughts exactly; his phrase is incomplete, but he seems to understand the process.

He means: "If we transform segments FP, FO by rotation of $90^{\circ}$ for any arbitrary point $\mathrm{F}$, then point $\mathrm{T}$ will remain in the same position", something that the researcher understood after the following procedure. He takes the mouse and inserts a point $F$ on segment FE. Point $F$ is positioned randomly on the segment. It can be animated or dragged anywhere on the segment, but will not leave the path. Then he rotates the segment FP by $90^{\circ}$ about center $\mathrm{P}$, and segment FO by $90^{\circ}$ about center $\mathrm{O}$. The construction of the rotations that $\mathrm{M}_{1}$ employs confirms his hypothesis with regard to point $\mathrm{T}$, which does not move. The trace and hide/show tools affected the way the student thought, leading him to formulate a conclusion and then to rotate the segments. Using the trace command, the student can observe that all the lines KL pass through point $\mathrm{T}$, and that point $\mathrm{T}$ remains constant. Using the hide/show tool, the student can hide the lines and render them visible once more through experimentation. The instrumentation process proceeding through the tools affects and shapes the way the user thinks, while the student also exerts an affect on the tools and acts by formulating his thoughts through the instrumentalization process. The student structures a usage schema in order to use the tool while simultaneously organizing his activity through the tool's own utilization schema. The formulation of the student's thoughts includes a hidden "if... then" expression. Consequently, the student was led to formulate an expression which determines level 3. The fact that he has not formulated his expression with clarity is due to his inability to remain stable at this level.

Field note 3: We follow these next steps to create a rotation in Sketchpad: to begin with, we select the point which will act as the center for rotation and define it on the transform menu as 'mark center'. Then we select the object we would like to rotate based on an angle, choosing the specified angle $\left(90^{\circ}\right)$. When the command runs, a new object is created which is a rotated image of the original object. For example, if a student decides to rotate a segment belonging on a line, s/he will not be able to accomplish the procedure if s/he doesn't construct the segment by defining it by means of its endpoints. This is a technical detail of the software which operates effectively as a direct connection between the theory (segment definition) and the user interface. The researcher did not consider it necessary "to separate the 'teaching of mathematics' from the 'teaching of the tool', preferring to integrate the appropriation of the functioning of a tool with the learning of the mathematics" (Olivero \& Robutti, 2007). For example, the process of rotating a segment by specifying a mark angle of $90^{\circ}$ and marking point $\mathrm{F}$ as the centre results in a segment the same length as the original segment but rotated through $90^{\circ}$ (it is vertical to the initial segment). Any effort to modify the length of the original segment by dragging its endpoints will result in an equivalent modification of the dependant rotated segment due to transformation (in our case, rotation). This transformation has a significant impact: during the instrumental approach, the student structures a utilization scheme of the tool, and consequently a mental image of the functional/operational process of rotation, since any modification/ transformation of the initial segment (input) results in the modification/transformation of the final segment (output). The instrument includes both the artefact and the mental schemes, which the student develops to be able to use the artefact efficiently. In such mental schemes technical and conceptual aspects are interwoven (Drijvers, 2003)

At this point, the researcher recasts the questions for the students: a) how can we find the treasure now the flag has disappeared?, and $b$ ) how can we prove that point $T$ is always fixed? The students drag point $\mathrm{F}$ until it almost touches the midpoint of segment $\mathrm{PO}$. 
203. $M_{2}$ : It is a rectangle, because the lines are perpendiculars (at the same line) therefore the angles are $90^{\circ}$, so these are parallel lines. (Figure 6)

\begin{tabular}{|c|c|}
\hline Student $\mathrm{M}_{2}$ & Analysis of the student's verbal formulation \\
\hline It is a rectangle & -Recognition with \\
\hline because & -justification (Reasoning) \\
\hline the lines are perpendiculars & $\begin{array}{l}\text {-a utilization scheme derived from the use of } \\
\text { the rotation command }\end{array}$ \\
\hline therefore the angles are $90^{\circ}$ & $\begin{array}{l}\text {-an inferential relationship between perpedi- } \\
\text { cularity and the angles } \\
\text {-Usage scheme for rotation by } 90 \text { degrees }\end{array}$ \\
\hline so these are parallel lines & $\begin{array}{l}\text {-Pupil expresses the relationship between } \\
\text { perpedicularity and parallelism which is to } \\
\text { say a } \\
\text { interrelationship between meanings (level } 3 \text { ) }\end{array}$ \\
\hline
\end{tabular}

Field note 4: student M2 speaks quickly pointing to the angles as if she has discovered something. She expresses her thoughts spontaneously rather than logically. The right order would be "the angles are 90 degrees, so the lines are perpendicular, which means this figure is a rectangle". The correlation between the psychological component of the instrumental approach and the meaning of 'gestures', as defined by Guin and Trouche (2002), is a way of correlating internal and external phenomena during instrumental genesis. Edwards (2005, p.5) claims that gesture can be considered a bridge between imagery and speech, seeing gesture as an intermediate link bringing together 'action, visualization, memory, language and written inscription'.

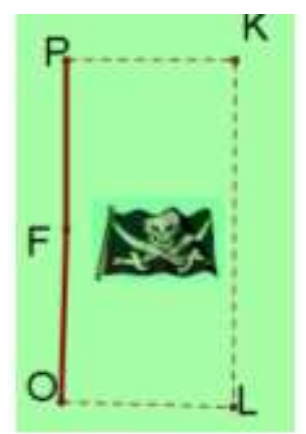

Figure 6

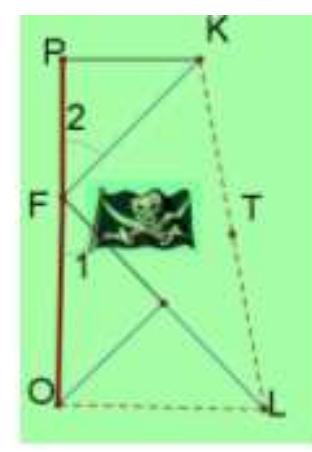

Figure 7

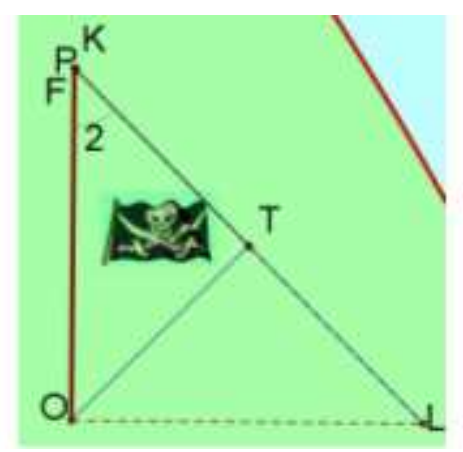

Figure 8

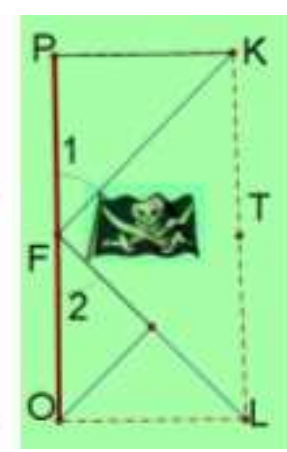

Figure 9

Representations of students's discussions 
204. $M_{2}$ : If we join point $F$ and $T$ this line will be an axis of symmetry. Point $F$ is the midpoint, FT is the perpendicular bisector because it is an axis of symmetry, so TP=TO.

\begin{tabular}{|l|l|}
\hline Student $\mathrm{M}_{2}$ & Analysis of the student's verbal formulation \\
\hline If we join point $F$ and $T$ & $\begin{array}{l}\text { If ...then statement ( level 3) } \\
\text { this line will be an axis of symmetry }\end{array}$ \\
$\begin{array}{l}\text {-Connection of the meaning of axis of sym- } \\
\text { metry with the shape, due to equality of the } \\
\text { segments } \\
\text {-Interrelationship between figures (level 3) }\end{array}$ \\
\hline
\end{tabular}

205. $M_{1}$ : Then everybody can move on the perpendicular bisector as it is the midpoint of segment $P O$ this distance (he points out the segment $P K$ )

\begin{tabular}{|l|l|}
\hline Student $\mathrm{M}_{1}$ & Analysis of the student's verbal formulation \\
$\begin{array}{l}\text { Then everybody can move on the perpen } \\
\text { dicular bisector }\end{array}$ & $\begin{array}{l}\text { The pupil expresses the exact solution of the } \\
\text { problem }\end{array}$ \\
$\begin{array}{l}\text { as it is the midpoint of segment } P O \\
\text {-Pre-existing knowlege } \\
\text {-expression of a relationship between the } \\
\text { perpendicular bisector and the midpoint of } \\
\text { the segment } \\
\text {-appropriate terminology for the description } \\
\text { (level 2) }\end{array}$ \\
\hline
\end{tabular}

\section{Group B:}

Field note 5: group $B$ consists of students $\mathrm{M}_{3}, \mathrm{M}_{4} . \mathrm{M}_{3}$ is a male student (van Hiele level: 2 ) and $\mathrm{M}_{4}$ is a female student (van Hiele level: 2 transition 3). The session lasted almost 15 minutes. Students picked a random location for the flag point $\mathrm{F}$ on the segment PO and they dragged it, showing that regardless of F's position the treasure's position is always immovable.

206. $M_{3}$ : the triangles $P K F, F O L$ are isosceles and right triangles. (Figure 7)

\begin{tabular}{|l|l|}
\hline Student $\mathrm{M}_{3}$ & Analysis of the student's verbal formulation \\
\hline are isosceles and right triangles & -Instrumented action scheme evoked by the \\
& use of the tool -rotation of a segment by 90 \\
degrees & -Appropriate terminology for the description \\
of the figure
\end{tabular}

207. $M_{4}$ : the triangle $K F L$ is a right triangle because the angles $F_{1}=F_{2}=45^{\circ}$, so the angle $K F L$ is equal with $90^{\circ}$

\begin{tabular}{|l|l|}
\hline Student $\mathrm{M}_{4}$ & Analysis of the student's verbal formulation \\
\hline the triangle KFL is a right triangle & utilization scheme \\
\hline because the angles $F_{1}=F_{2}=45^{\circ}$ & $\begin{array}{l}\text {-Pre-existing knowledge } \\
\text {-justification (Reasoning) } \\
\text {-relationship between properties }\end{array}$ \\
\hline so the angle KFL is equal with $90^{\circ}$ & -Consclusion and expression of a relationship \\
\hline
\end{tabular}


208. $M_{3}$ : if we construct the median of the triangle $F O L$, joining the vertex $O$ with the midpoint of the opposite side FL. ...

Field note 6: $M_{3}$ drags point $F$ until it coincides with point $P$. He notes that the extension of the median could pass through point $\mathrm{T}$ (the site of treasure). He confirmed his conjecture by dragging point $\mathrm{F}$ so that it coincides with point $\mathrm{P}$.

209. $M_{3}$ : the triangle is a right and isosceles one and the median is equal to the half of hypotenuse. So $O T=K L / 2$ (Figure 8)

\begin{tabular}{|l|l|}
\hline Student $\mathrm{M}_{3}$ & Analysis of the student's verbal formulation \\
\hline $\begin{array}{l}\text { if we construct the median of the triangle } \\
\text { FOL, joining the vertex } \mathrm{O} \text { with the midpoint } \\
\text { of the opposite side } F L\end{array}$ & $\begin{array}{l}\text {-The pupil develops a strategy in order to } \\
\text { solve the problem }\end{array}$ \\
\hline $\begin{array}{l}\text { the triangle is a right and isosceles } \text { one and } \\
\text { the median is equal to the half of hypote- } \\
\text { nuse }\end{array}$ & $\begin{array}{l}\text {-Pre-existing knowledge of the theorems and } \\
\text { their correlation with the shape } \\
\text { He finds a solution to the problem. }\end{array}$ \\
\hline
\end{tabular}

210. Researcher: Do you know KL?

211. $\mathrm{M}_{3}$ : according to Pythagorean theorem KL is equal with the sum of the squares of the two vertical sides of the right triangle. KL is... (?)

212. $\mathrm{M}_{4}: K L=P O \sqrt{2}$ and $O T=P O(\sqrt{2} / 2$ )

\begin{tabular}{|l|l|}
\hline Students $\mathrm{M}_{3}, \mathrm{M}_{4}$ & \begin{tabular}{l} 
Analysis of the students' verbal formulation \\
\hline $\begin{array}{l}\text { according to Pythagorean theorem } K L \text { is } \\
\text { equal with the sum of the squares of the two } \\
\text { vertical sides of the right triangle }\end{array}$
\end{tabular} \\
$\begin{array}{ll}\text {-Pre-existing knowledge of Pythagoras' theo- } \\
\text { rem } \\
\text {-Longer sequence of statements (level 4) }\end{array}$ \\
$\begin{array}{ll}\text {-Direct calculation and relationship with } \\
\text { knowledge of the theorem, previously ex- } \\
\text { pressed by her schoolmate } \\
\text {-expression of the exact algebraic solution }\end{array}$ \\
\hline
\end{tabular}

Field note 7: M4 seemed to pay attention to everything that M3 said and spoke in turn. She completed M3's answer by calculating the correct length of segment KL using the Pythagorean Theorem. She then dragged point $F$ until it coincided with the midpoint of segment PO. Both students spoke very quickly and communicatively. It seemed that both knew the answers in advance, but had approached the solution in a different manner than the previous pair having spontaneous and quick reactions. The researcher felt like she was in the middle of a tennis game where the ball was moving very fast between them. She compared the behaviour of the same students when they faced a similar problem in a static medium where the students didn't express their thoughts instantaneously; they reached their conclusion slowly. 
213. $\mathrm{M}_{4}$ : If we drag $F$ to be the midpoint, then the triangles $K F T=F P K=F T L=T O L$ are all congruent and $F T$ is an axis of symmetry. ...Then $F T=F P$ so if $P O=x$ then $F T=x / 2$. (Figure 9)

\begin{tabular}{|l|l|}
\hline $\begin{array}{l}\text { Student } \mathrm{M}_{4} \\
\text { If we drag } F \text { to be the midpoint, then the } \\
\text { triangles }\end{array}$ & $\begin{array}{l}\text { Analysis of the student's verbal formulation } \\
\text {-If..then statement } \\
\text {-The pupil develops another strategy in order } \\
\text { to solve the problem }\end{array}$ \\
\hline $\begin{array}{l}\text { KFT }=F P K=F T L=T O L \text { are } \\
\text { all congruent }\end{array}$ & $\begin{array}{l}\text { She has constructed a mental scheme as a } \\
\text { result of the instrumented action scheme } \\
\text { constructed by the rotation command and her } \\
\text { pre-existing knowledge }\end{array}$ \\
\hline if $P O=x$ then $F T=x / 2$. & $\begin{array}{l}\text {-If ...then statement } \\
\text { - longer sequences of ststements (level 4) } \\
\text {-transformation into an algebraic expression } \\
\text {-an exact solution }\end{array}$ \\
\hline
\end{tabular}

Field note 8: In the dialogues, the phrases marked in bold are indicative of the students' levels. The students reached conclusions on the problem by correlating the theorems they already know. The software, however, helped the pupils overcome their obstacles and prove the specific cases of the problem. As Drijvers (2003) writes "The instrumentation schemes integrate technical skills and conceptual insights". We agree with Drijvers that we "cannot look inside the heads of the students to observe the mental schemes". For this reason, "we focused on the techniques, which can be considered as the observable parts of the instrumentation schemes".

\section{Didactical Analysis}

The same problem was presented, and the same key clarifications given, during a class lesson. Initially, the students worked individually and did not understand what could be done to find the solution. The results from the paper-pencil test showed that the students spent a long time (roughly 30 minutes) constructing lines and blotting their drawing without reaching a solution. In a session where the problem has been discussed during a classroom learning process, the researcher assumed that insufficient clarification had been given to the students in the initial paper and pencil test. The students did not return to the problem for a whole month. Then the researcher decided to readdress the same problem. She re-formulated the problem using a different way of approaching it which experimental group students had come up with during the sessions (e.g choosing to position the flag on the midpoint between the two trees by dragging).

The reformulated problem: "An archaeologist has an old map which explains the position of a clay pot: You walk directly from point $\mathrm{P}$ to point $\mathrm{F}$ (F, E are constant points) counting your paces as you go. Then turn right 90 degrees and walk the same number of paces from point $F$. When you reach the end, put a stick in the ground. Return to point $\mathrm{P}$ and walk directly to point $\mathrm{K}$, again counting your paces and turning left 90 degrees and walking the same number of paces. Put another stick in the ground. The vessel is buried in the middle of the distance of the two sticks.

Rejecting the procedure described above, the archaeologist did the following: starting from the midpoint of the segment FE, he followed the directions given on the map until he finally found the pot. a) Can you plot the shape according to the steps that archaeologist followed? And b) can you explain (using formal logic) why he was right?" 
Figures 10,11, 12 depict the sequence of constructive steps leading to the solution. The students had to follow these steps to prove the problem:

1. To find the midpoint $\mathrm{O}$ of the segment $\mathrm{FE}$

2. To construct the rotation of the segments FO, OE.

3. To connect the points A and B and observe that the segment AB passes through point $\mathrm{V}$ (position of the vessel)

4. To verify that points $\mathrm{A}, \mathrm{V}$ and $\mathrm{B}$ are collinear

5. To verify that point $\mathrm{V}$ is the midpoint of segment $\mathrm{AB}$ (Figure 11)

The solution of the problem is the following:

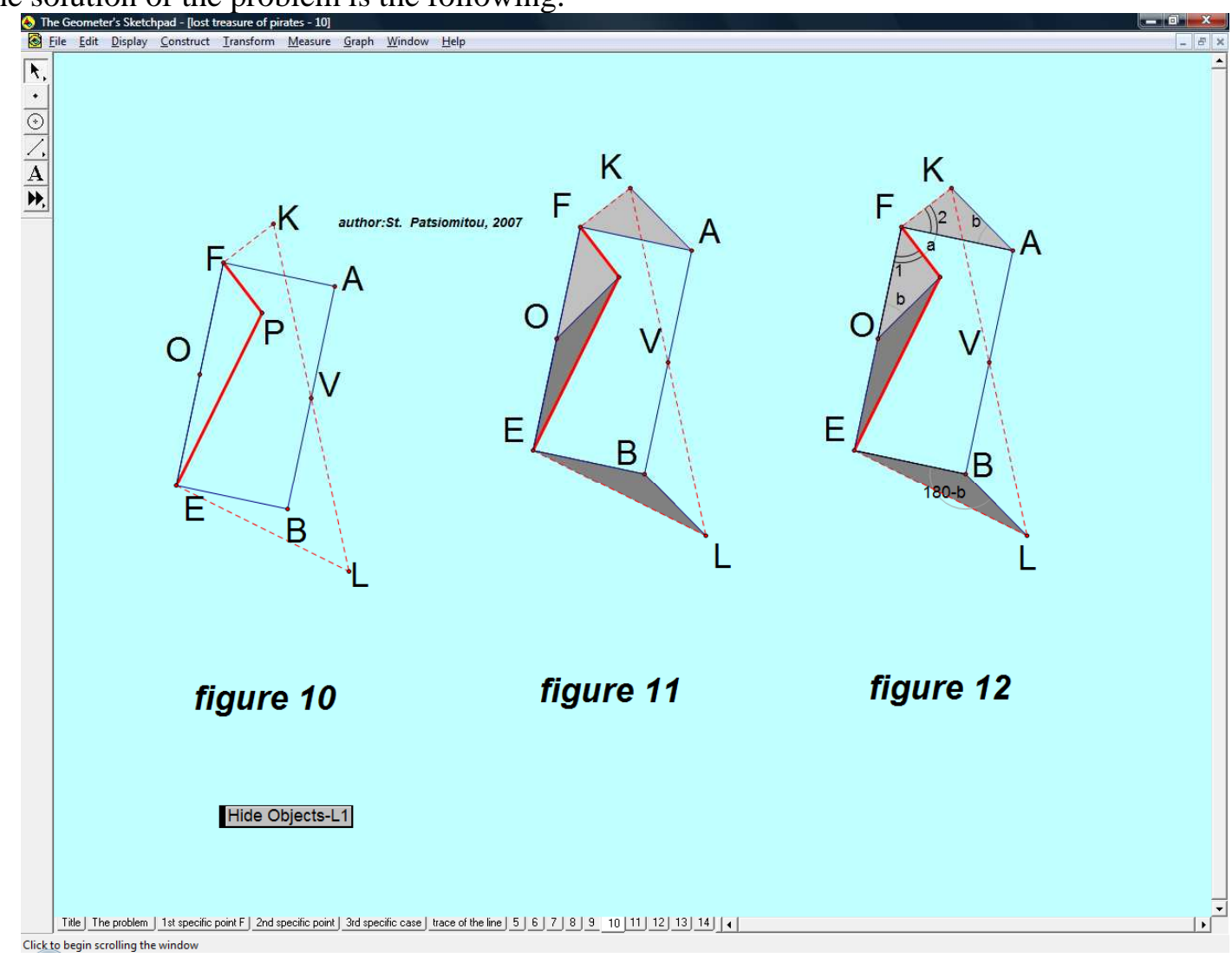

Figure 10

Figure 11

Figure 12

Sequence of constructive steps leading to the solution

We must prove that the shape KALB is a parallelogram (Figure 12). For this we have to verify that the opposite sides KA, LB are parallel and equal. KA=OP (from the comparison of the congruent triangles $\mathrm{FOP}, \mathrm{FAK}$ ). And $\mathrm{BL}=\mathrm{OP}$ (from the comparison of the congruent triangles $\mathrm{OPE}$, $\mathrm{EBL}$ ) while the angle $\angle \mathrm{KAB}=\angle \mathrm{ABL}=90^{\circ}+\mathrm{b}$ (Figure 12). So the quadrilateral KALB is parallelogram and $\mathrm{AB}$ dichotomize $\mathrm{KL}$, consequently the points $\mathrm{A}, \mathrm{V}, \mathrm{B}$ are collinear and the point $\mathrm{V}$ is the midpoint of the segment $\mathrm{AB}$.

The researcher revealed neither the solution nor the shapes on it to the students before posing the problem using static means.

Consequently, the following research questions can be posed: 
5. Can the students in the experimental and control teams complete the diagram by following the route taken by the archaeologist? Or in other words

Which group responded more correctly to the problem representation?

6. Were the decision/problem strategies adopted by the students in the experimental team during the software problem-solving process conscious?

7. Can the students in the experimental or control team be induced to apply productive reasoning?

Each student had roughly 20 minutes to solve the problem.

\section{Research with Static Means}

In this section, differences between the two teams in terms of completing the representation of the problem will be briefly presented. In this way, we will be able to derive conclusions on the students' understanding of problem formulation relating to the meaning of rotation in tandem with their formal reasoning during problem discovering and solving. Some representative examples of students' shapes are shown in Table A. The first line includes examples from the experimental team; examples from the control team are included in line three. On the second line, the students' levels are displayed so one may directly observe the cross-correlations and differences with regard to construction. We can therefore conclude that:

Examples of experimental team's represenatations

The students in the experimental team followed sufficient steps in their approach to the solution. Irrespective of their van Hiele level, they made a correct shape, which proves they understood the meaning of "rotation of a segment". In the experimental group, students who explored the prob- 
lem through dynamic representations proceeded to the proof, while the rest made worthy attempts by trying to reach conclusions using the mode of construction (one female student, for example, identified the axis of symmetry and from this reached a conclusion as to the position of the clay pot). Their actions were relative to those involved in the software sessions; despite their not having re-examined the problem in the interim, the students were able to recall their actions as though they related to a recent task. The students' constructions and answers allow us to conclude that they had operated and found the solution using a mental construction (or a series of recalled images). The level of the pupils with regard to their degree of success in construction as well as reasoning (we can see the representations Table A) was of decided importance.

The students with levels 1 and 2 have comprehended and drawn the representation of the problem correctly, highlighting the congruent correlated segments on their depiction. Their construction of the rectangle matches Figure 1 in the didactical analysis. From level 2 up, the students also explain the process they used to solve the problem. The students in the control group did not successfully construct the shape, and most did not understand the meaning of "rotating left/right by 90 degrees". We even observed errors in the recognition of segments pupils considered equal. No one achieved the proof, and their efforts were purely accidental.

We shall limit ourselves to analyzing the behaviour of the three most advanced students. We shall therefore examine and analyze the mental approach taken by two students from the experimental and one from the control group to proving the solution to the problem.

Student Y: Student Y didn't produce correct constructions in earlier tests. His diagram reveals that: a) He has understood the problem, since he made a successful attempt at constructing and solving it. The instrumentation procedure and utilization schemes resulting from the use of the software's rotation command guided him to an understanding of the $90^{\circ}$ rotation / turn. He applied a research method in his use of the software; encountering a cognitive obstacle, he came up with a reverse solution to the problem. As a result, he produced a complex construction on paper which students at a higher level that Student $Y$ failed to construct. He continued by comparing the two triangles and concluding that their sides were of equal length. This comparison reveals the conscious use of productive thinking. Student $Y$ has proved the problem for the specific case of the rectangle by recognizing the congruent isosceles and right triangles, highlighting the angle of 45 degrees on the diagram.

Student X: Student X constructed a mental image of the way in which part of the figure rotates, and this helped him to solve the problem. Connecting $\mathrm{P}$ and $\mathrm{P}^{\prime}$, he compared the two triangles. $\mathrm{X}$ 's approach is different from that in the software. The student has understood that he has to compare the two groups of triangles if he is to solve the problem. His comparison is accurate and, confirms our earlier intuition that the student has constructed a mental model of the rotation of part of the figure, as this is how he sets about proving that these parts are actually equal. Student $\mathrm{X}$ has generalized: his drawing is complex. We can observe that his proof and the drawing are similar to the shape constructed by the researcher in Figure 12.

Student Z: The Student is able (van Hiele level 3 in the examples above). The diagram she produces is incorrect. Her construction of the rotation is incorrect, as the two segments that result are not equal. The remainder of her solution and proof lack any underlying rationale: she does not mention a rectangle, but rather a shape (it isn't clear what shape exactly).

\section{Research Process (using LVAR)}

As mentioned in a previous section, LVAR is the process of proving the concrete problem made up of a series of steps which can function as a response, anticipating questions posed explicitly or implicitly by the teacher (or student). 
During the inquiring process the researcher acted as a co-actor in/co-ordinator of the activity, assuming the role of the teacher, coordinating the discourse and leading pupils towards the Euclidean proof. The pupil participants are guided through the discussion and by the multiple pages of the Sketchpad file towards the interaction techniques. Alternatively, the students could react spontaneously using the mouse. The students discovered the solution strategies relating to specific points chosen by them thereafter have been motivated by the researcher to interact with the semi pre-designed problem by her in the multiple pages. The semi-predesigned problem contained as much information as was needed to get the students to think, explore and treat Maths like a game, and thus helped them mentally construct a new meaning or image by processing their extant knowledge of the theorems. The researcher designed the problem in the software's multiple pages using LVAR in the light of her observations of the way pupils develop learning processes in mathematics-i.e. that they return to a previous step in the construction process because this allows them to reorganize their thoughts, and because it feeds back to their future actions. Key points from the peer sessions are detailed below. Each and every new discovery is greeted with enthusiasm. The points in the dialogues at which the researcher observed the RVR are also noted, along with the points at which utilization schemes were constructed by the students. The phrases marked in bold correspond are indicative of the levels of the students.

As the images below illustrate, the researcher took care to highlight the equal segments or the equal triangles with the same colour, which would appear in the students' correct answer when pressing a hide-show button.

Within this theoretical framework, two more significant research questions are posed:

\section{Research Questions:}

8. To what degree can LVAR contribute to the students constructing rigorous Euclidean proofs?

9. To what degree can LVAR assist students improve /develop their van Hiele level?

\section{A pair's session}

\section{Group A:}
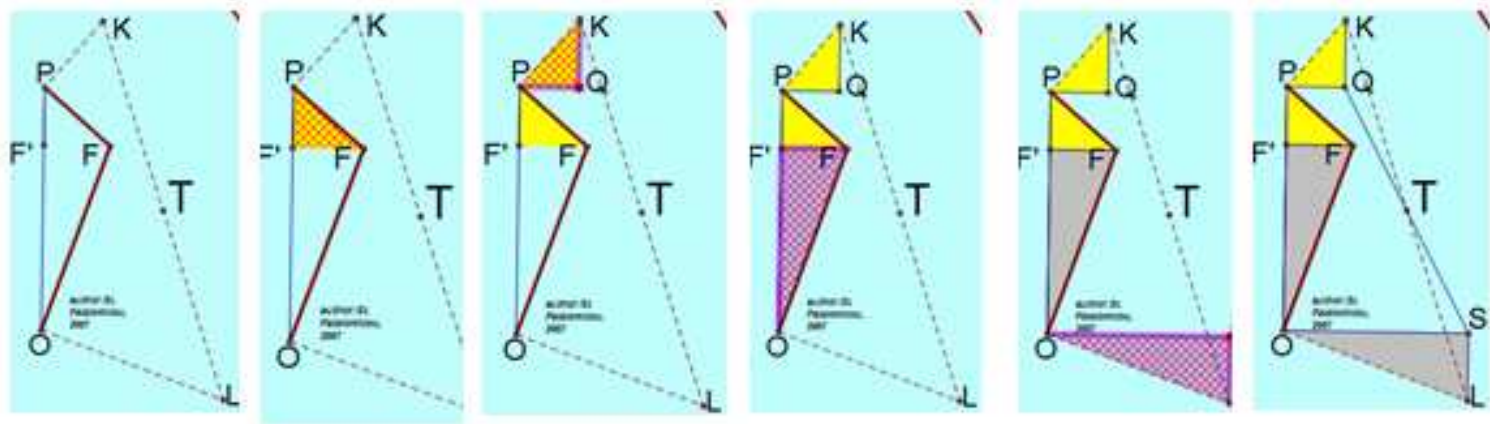

Figure 13. Sequential phases of the Linking Visual Active Representations of the figure 13

Field note 1: is constituted from pupils $\mathrm{M}_{1}, \mathrm{M}_{2} . \mathrm{M}_{1}$ is a male pupil (van Hiele level: 1 at the pretest) and $\mathrm{M}_{2}$ is a female pupil (van Hiele level: 2 at the pre-test) tested about 4 months ago.

214. $\mathrm{M}_{2}: P Q S O$ is a trapezium because $P Q$ and $S O$ are perpendiculars to $P O$ as we concluded from the rotation for $90^{\circ}$....we must prove that $T$ is the midpoint of any segment that can be. Will we join $K$ and $S$ ? .... These (pointing to $K L, Q S$ ) seem to be diagonals but where is 
the quadrilateral ...If we prove that $K L, Q S$ are the diagonals of a parallelogram then the diagonals are dichotomized.... . But we have to find first the parallelogram... (Figure 13)

\begin{tabular}{|c|c|}
\hline Student $\mathrm{M}_{2}$ & Analysis of the student's verbal formulation \\
\hline$P Q S O$ is a trapezium & recognition and classification of the figure \\
\hline because & justification (Reasoning) \\
\hline$P Q$ and $S O$ are perpendiculars to $P O$ & $\begin{array}{l}\text {-RVR } \\
\text {-Formulation of a relationship between the } \\
\text { segments } \\
\text { which implies that } \\
\text { the pupil already knows that two perpedicular } \\
\text { lines are parallel, namely a connection with } \\
\text { her previous knowledge } \\
\text {-interrelationship between properties (level 3) }\end{array}$ \\
\hline $\begin{array}{l}\text { as we concluded from the rotation for } \\
90^{\circ}\end{array}$ & Utilization scheme of the rotation command \\
\hline we must prove & $\begin{array}{l}\text { Need to prove -the student understands of } \\
\text { significance of deduction }\end{array}$ \\
\hline $\begin{array}{l}\text { Tis the midpoint of any segment that can } \\
\text { be }\end{array}$ & Generalization \\
\hline $\begin{array}{l}\text { These (pointing to } K L, Q S \text { ) seem to be } \\
\text { diagonals but where is the quadrilateral }\end{array}$ & $\begin{array}{l}\text { RVR } \\
\text { Connection of the diagram with the rela- } \\
\text { tioship that diagonals of any parallelogram } \\
\text { has }\end{array}$ \\
\hline $\begin{array}{l}\text { If we prove that } K L, Q S \text { are the diagonals } \\
\text { of a parallelogram }\end{array}$ & -If ...then statement \\
\hline then the diagonals are dichotomized & Properties of the shape \\
\hline $\begin{array}{l}\text { But we have to find first the parallelo- } \\
\text { gram... }\end{array}$ & $\begin{array}{l}\text { The pupil does not have a diagram before her } \\
\text { and has to conclude the shape of the paral- } \\
\text { lelogram from the diagonals, which means } \\
\text { that she has constructed a mental scheme }\end{array}$ \\
\hline
\end{tabular}

215. $\mathrm{M}_{2}$ : we want to prove that this is a parallelogram (pointing to $Q K S L$ )... This is a common side of the triangles (meaning $F F^{\prime}$ ) these will be equal,so we will have the opposite sides to be equal which means $F F^{\prime}=Q K=L S \ldots$ But we have to prove that these (meaning $Q K, S L$ ) are parallel lines

\begin{tabular}{|l|l|}
\hline Student $\mathrm{M}_{2}$ & Analysis of the student's verbal formulation \\
\hline $\begin{array}{l}\text { This is a common side of the triangles } \\
\text { (meaning } F F^{\prime} \text { ) these will be equal ,so }\end{array}$ & $\begin{array}{l}\mathrm{RVR} \text { from the construction of the diagram } \\
\text { we will have the opposite sides to be } \\
\text { equal which means } F F^{\prime}=Q K=L S \ldots\end{array}$ \\
$\begin{array}{l}\text { compared the triangles without using a pa- } \\
\text { per-pencil design }\end{array}$ \\
$\begin{array}{l}\text { But we have to prove that these (mean- } \\
\text { ing } Q K, S L \text { ) are parallel lines }\end{array}$ & $\begin{array}{l}\text { In other words, the student has to work } \\
\text { backwards in search of a relationship that } \\
\text { would allow it to be a parallelogram. }\end{array}$ \\
\hline
\end{tabular}


216. $\mathrm{M}_{1}$ : if we prove that these are parallel lines then the quadrilateral is a parallelogram because these are equal, so the diagonals will be intersected, so the diagonals will be dichotomized

\begin{tabular}{|c|c|}
\hline Student $\mathrm{M}_{1}$ & Analysis of the student's verbal formulation \\
\hline if we prove that these are parallel lines & -Conjecture, if ...then statement \\
\hline $\begin{array}{l}\text { then the quadrilateral is a parallelo- } \\
\text { gram }\end{array}$ & $\begin{array}{l}\text {-Relationship between the shape and its sides } \\
\text { properties of the figure }\end{array}$ \\
\hline because these are equal & $\mathrm{RVR}$ - semperasma \\
\hline so the diagonals will be intersected & -Complex way of thinking \\
\hline so the diagonals will be dichotomized. & -Formulation of the figures's properties \\
\hline
\end{tabular}

217. $\mathrm{M}_{2}$ : we must prove that these are right triangles (points out the triangles PFF', OSL ...) ...but they are (right) because we have constructed them with the rotation.

\begin{tabular}{|l|l|}
\hline Student $\mathrm{M}_{2}$ & Analysis of the student's verbal formulation \\
\hline $\begin{array}{l}\text { we must prove that these are right tri- } \\
\text { angles }\end{array}$ & $\begin{array}{l}\text { - the student understands of significance of } \\
\text { deduction (level 4) }\end{array}$ \\
\hline $\begin{array}{l}\text { but they are (right) } \\
\text { because }\end{array}$ & -utilization schema (RVR) \\
\hline $\begin{array}{l}\text { we have constructed them with the rota- } \\
\text { tion. }\end{array}$ & - -a mental scheme \\
\hline
\end{tabular}

Field note 2: $\mathrm{M}_{1}$ displays behaviour associated with a higher van Hiele level when he uses geometric terminology to express his thoughts. He analyzes $\mathbf{M}_{2}$ 's conclusion, using it to as his starting point and working backwards. The student notes the shape and thinks out loud, producing a complex sentence including an 'if...then' statement. He also expresses an inverse relationship he needs to prove the validity of his statement, as well as a cogent argument, meaning a series of linked statements leading to a final "semperasma"/conclusion.

The word "semperasma" is defined in Greek dictionaries as "a new thought formed from given data". 'Semperasma' is also Aristotle's term for something intended to follow on logically from given premises, or a logical conclusion affirming the protasis, or in other words what results of necessity, and also a terminology used when the Euclidean proof is accomplished. That his statements are logically linked, allows us to posit that his van Hiele level is in transition to a higher level.

When $\mathrm{M}_{2}$ discovered the parallelogram, she points to the shape, expresses the relationship between the meaning of perpendicular lines and the constructed rotation of the triangle by setting 'mark angle' to $90^{\circ}$. Her expression "we must prove" shows that she understands the significance of deduction in solving the problem. The logical reasoning and the appropriate use to which the pair put hypothesis/semperasma or analysis and synthesis of their thoughts, is in accordance with a higher van Hiele level than that revealed in the pre-test. 


\section{An orchestration of the group and the LVAR on the multiple pages of the software}

Field note 3: The experimental group consists of pupils $M_{1}$ to $M_{14}$. The teaching session was designed to record how students with no prior experience of the given problem would react as they interacted with the LVAR. The researcher's aim was to adapt the experiment to real classroom conditions. It was crucial that students completed the proof during the experimental procedure by taking their partners' thinking further as they sat around the PC with the researcher among them. The researcher had connected a projector to her own computer, and pupils could actively participate by interacting with the multiple-page pre-constructed activity.

All the students were free to click on and use the software tools to take an active part in the activity, and their contribution was the subject of discussion among the students. In that way, the mistakes made and the approach taken by each student could be seen by all, and they could all actively participate in the procedure; as a result, the class was more like a playgroup than a mathematics class working to strictly find proof. As they took part in the process and contributed to the proof by answering the researcher's questions, they added to it by explaining their conjecture, which was connected with the appearance of an additional constructive procedure that would appear. During the classroom experimental session, the researcher strove to activate those students that had not participated in solving the lost treasure problem during the pair-work phase, encouraging them to state and share their views. For example students $M_{7}$ to $M_{10^{-}}$-the students who had the highest RVR--had been involved in solving other problems, but had never done so in the multiple linking pages provided by the software. The process effectively stimulated cooperation as the team as a whole struggled to solve the problem in the best way they could. A presentation of the session's most important points, at which the pupils answered crucial questions, follows below. The session was approximately 25 minutes long.
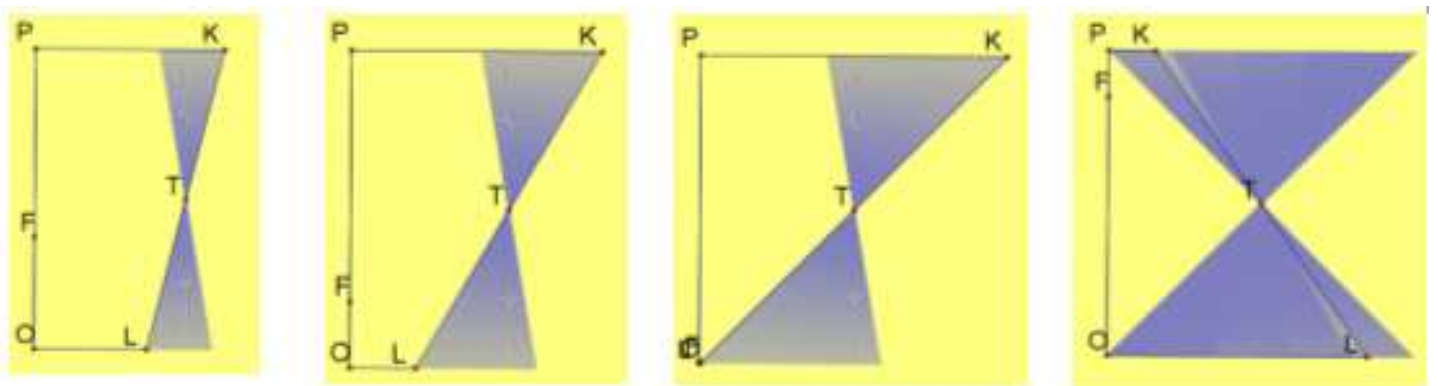

Figure 14. Sequential phases of Figure 14 while point $\mathrm{F}$ is animated and KL is traced

Working on figure 14

218. Researcher : Which is the position of point $T$ as we drag point $F$ ?

$(R V R)$

219. $\mathrm{M}_{4}$ : it is the symmetry centre of the shape

220. R: Can you conjecture what kind of quadrilateral is shaped with the traces as we drag point $F ?$

- (utilization scheme)

221. All the pupils: it seems a square

(RVR)-(social scheme)

Field note 4: When a pupil interacts with the visual representation he can visualize the sequential steps of all the visual representations that appear during the animation of point $\mathrm{F}$ as the segment $\mathrm{KL}$ is being traced. Besides the pupil verifies visually that the distances KT,TL remain equal as proint $\mathrm{F}$ is moved and that it remains the midpoint of $\mathrm{KL}$ for every point $\mathrm{F}$. 
This process results in a connection between the 'spatio-graphical' and the 'theoretical field' as C. Laborde (2005) describes. The pupils react to this visual stimulus and respond instadaneously. Their responce is a result of the reaction which occurs to the visual stimulus.

The depicted representations lead the pupils to construct a more sophisticated representation which reflects the shape of a square. This process leads the pupils to connect the LVAR with the meanings of the centre of symmetry and the square. At the same time this process results in the pupil visually connecting the meaning of the square with the equality of the diagonals and the equality of its sides $-i$.e a relationship between the two meanings.

Then, the sequence of diagrams leads to the gradual formulation of expressions relating to the problem's solution, since the student is led to form expressions like those formed by student M7. The resultant LVARs lead the student to a reflexive mode of thought which results in their connecting the images (i.e. the visualization) with productive thinking and the reasoning required for the proof process.

231. R: can you find what the equal segments are?

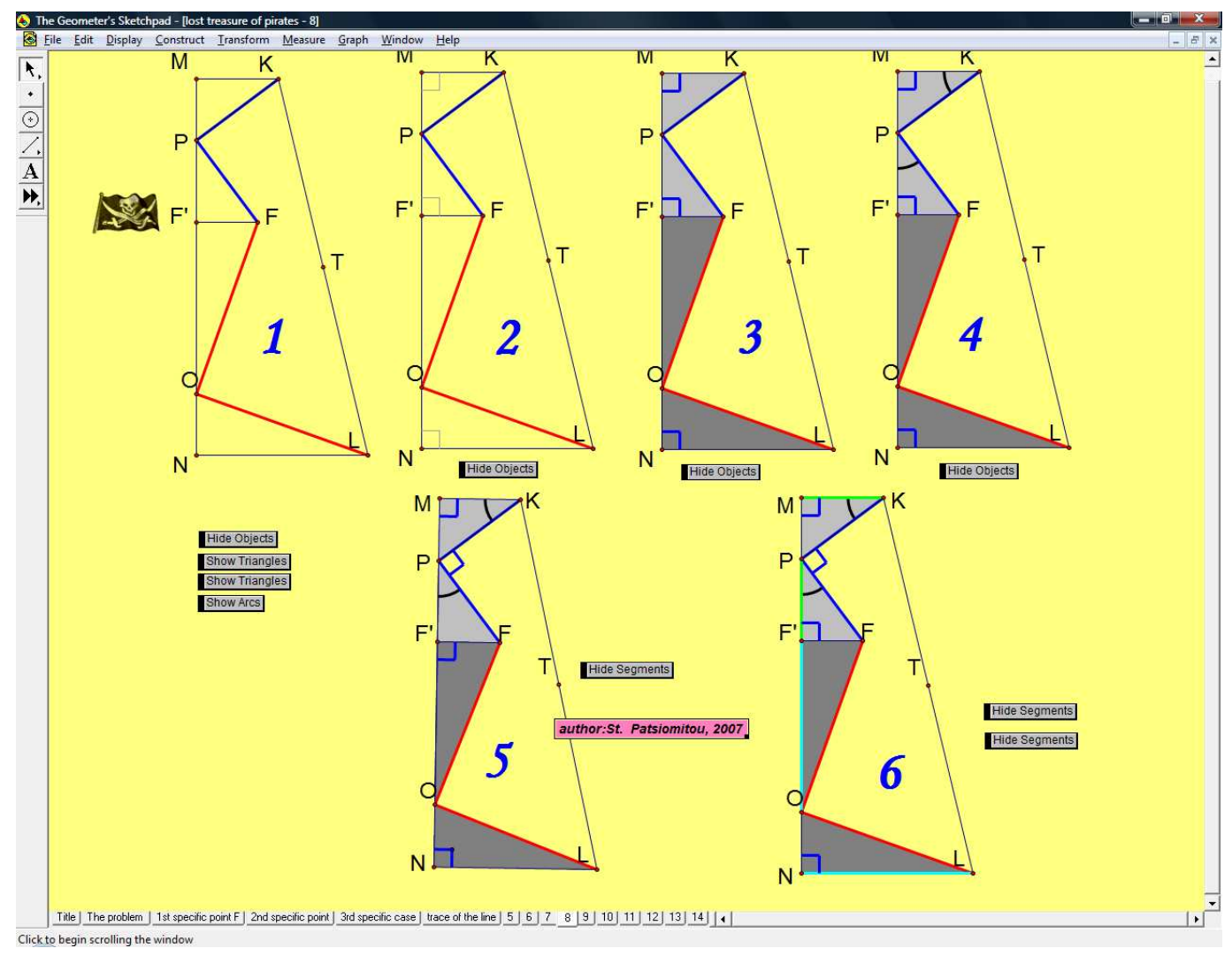

Sequential phases of Figure 15 from the depicted LVAR 
232. $\mathrm{M}_{7}$ : the segments $M K$ and $P F^{\prime}$ are equal, because the triangles $M K P \kappa \alpha l F F^{\prime} P$ are congruent as they are right triangles, (mental scheme) they have $K P=P F$, and angle $<M K P$ is equal to $\left\langle F P F^{\prime}\right.$ angle - because $\left\langle K P F^{\prime}\right.$ angle is external to the triangle MKP so it is constituted from an angle of $90^{\circ}$ and the angle $\angle F P F^{\prime}$ so it is equal with the opposite angles $<\left(M K P+90^{\circ}\right)($ Figure 15)

\begin{tabular}{|c|c|}
\hline Student $\mathrm{M}_{7}$ & Analysis of the student's verbal formulation \\
\hline $\begin{array}{l}\text { the triangles } M K P \kappa \alpha l F F^{\prime} P \text { are congru- } \\
\text { ent }\end{array}$ & RVR \\
\hline $\begin{array}{l}\text { Because, and angle }<M K P \text { is equal to } \\
<F P F^{\prime} \text { angle }\end{array}$ & $\begin{array}{l}\text { Justification - connection with prior knowl- } \\
\text { edge of theorems (criteria for congruent tri- } \\
\text { angles) }\end{array}$ \\
\hline they are right triangles & RVR (reflection from the diagram) \\
\hline they have $K P=P F$ & $\begin{array}{l}\text { Utilization scheme constructed from the use } \\
\text { of the rotation command }\end{array}$ \\
\hline angle $<M K P$ is equal to $<F P F^{\prime}$ angle & RVR (reflection from the diagram) \\
\hline because & justification \\
\hline $\begin{array}{l}\angle K P F^{\prime} \text { angle is external to the triangle } \\
M K P\end{array}$ & Connection with prior knowledge \\
\hline $\begin{array}{l}\text { so it is constituted from an angle of } 90^{\circ} \\
\text { and the angle }<F P F^{\prime}\end{array}$ & RVR (reflection from the diagram) \\
\hline $\begin{array}{l}\text { so it is equal with the opposite angles } \\
<\left(M K P+90^{\circ}\right)\end{array}$ & $\begin{array}{l}\text { RVR (reflection from the diagram) } \\
\text {-the student understands of significance of } \\
\text { deduction (level 4) } \\
\text {-Longer sequence of statements (level 4) }\end{array}$ \\
\hline
\end{tabular}
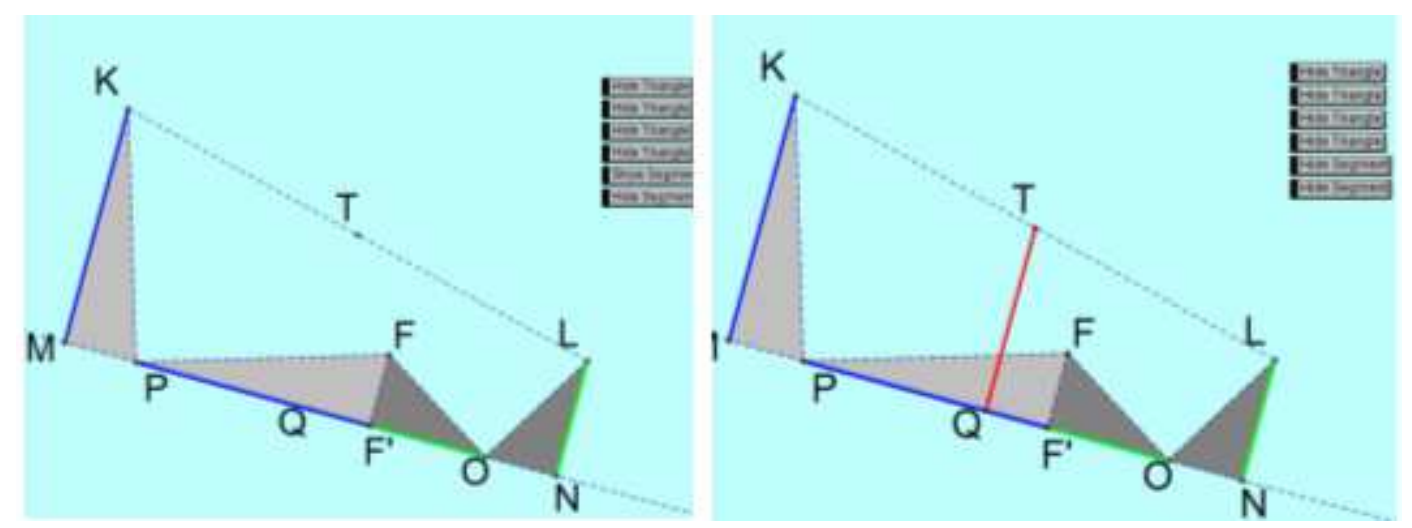

Sequential phases of the figure 16

Field note 5: $\mathrm{M}_{7}$ 's response impressed the researcher, though she had never responded so immediately in traditional classes prior to the sessions. Her answer was spontaneous, instantaneous, and related to the reflection from the diagram since she did not have time to use paper and pencil as the researcher's questions were continuous and repeated rapidly. The researcher's observations reveal that it was not always the same pupils who displayed the same spontaneous reflex reac- 
tions. The pupils then moved on to constructing lines rising perpendicularly from points $\mathrm{K}$, $\mathrm{L}$ to prove that the treasure's position is unrelated to the location of point $\mathrm{P}$. As their answers prove, they had linked the previously presented actions to the constructional or transformational actions on the current page.

(Figure 16)

233. $\mathrm{M}_{3}$ : angle $M K P$ is equal to angle FPF' because their sides are vertical.

$(R V R)$

234. R: Which of the segments are also equal ?

235. All the pupils: $L N$ and $O F$ '

(RVR)-(social scheme)

236. $\mathrm{M}_{8}$ : the sum $K M+L N=P O=P F^{\prime}+F^{\prime} O$

237. $\mathrm{M}_{8}$ : the quadrilateral $K M N L$ is a trapezium and $T Q$ is equal with the sum $(K M+L N) / 2$. But $K M+L N=P F^{\prime}+F^{\prime} O=P O$, so the segment $T Q$ is the half of the segment $P O$.

\begin{tabular}{|c|c|}
\hline Student $\mathrm{M}_{8}$ & Analysis of the student's verbal formulation \\
\hline the quadrilateral KMNL is a trapezium & Recognition-visualization \\
\hline$T Q$ is equal with the sum $(K M+L N) / 2$ & $\begin{array}{l}\text { connection with prior knowledge } \\
\text { (correlated theorem) }\end{array}$ \\
\hline But $K M+L N=P F^{\prime}+F^{\prime} O=P O$ & Connection -linking with the previous page \\
\hline $\begin{array}{l}\text { so the segment } T Q \text { is the half of the seg- } \\
\text { ment } P O\end{array}$ & $\begin{array}{l}\text { Productive reasoning (if } T Q \text { is equal with the } \\
\text { sum }(K M+L N) / 2, K M+L N=P O \\
\text { then } T Q \text { is the half of the segment } P O \\
\text { - the student understands of significance of } \\
\text { deduction (level } 4) \\
\text {-Longer sequence of statements (level 4) }\end{array}$ \\
\hline
\end{tabular}

238. R: Why the segments $M P, O N$ are equal?

239. $\mathrm{M}_{8}$ : because they are equal with the segment $F F^{\prime}$

RVR-(utilization scheme)

Field note 6: Although the problem was open-ended, the students succeeded in formulating a semperasma which they had to prove. Students $\mathrm{M}_{7}$ and $\mathrm{M}_{8}$ reach conclusions on the problem by correlating the theorems they already know. The LVAR on multiple pages helped them react instantaneously and connect their thoughts. The transformations which occured due to techniques had a significant impact: during the instrumental approach, the student structured utilization schemes of the tools, and consequently mental images of the operational processes, since any modification/ transformation of the initial figure (input) resulted in the modification/transformation of the final figure (output). We can thus see that an inductive cognitive procedure had guided them to productive reasoning. An observation of students' answers would indicate that their answers are in accordance with a higher van Hiele level than that revealed in the pre-test. The pupils didn't use to applying theorems relevant to trapeziums in the pair-work session, because they were not familiar with the relative concepts. This allows us to conclude that prior knowledge is very important for teaching of this sort including a problem-solving scenario. 
A table listing the results observed for the students would reveal the following:

\begin{tabular}{|l|c|c|c|c|c|c|}
\hline \multicolumn{1}{|c|}{$\begin{array}{c}\text { Student's } \\
\text { action/behaviour }\end{array}$} & $\begin{array}{c}\text { M1 } \\
\text { Level 1 }\end{array}$ & $\begin{array}{c}\text { M2 } \\
\text { Level 2 }\end{array}$ & $\begin{array}{c}\text { M3 } \\
\text { Level 2 }\end{array}$ & $\begin{array}{c}\text { M4 } \\
\text { Level 2-3 }\end{array}$ & $\begin{array}{c}\text { M7 } \\
\text { Level 2-3 }\end{array}$ & $\begin{array}{c}\text { M8 } \\
\text { Level 2 }\end{array}$ \\
\hline Develops strategy & $\bullet$ & $\bullet$ & $\bullet$ & $\bullet$ & & \\
\hline $\begin{array}{l}\text { Structures utiliza- } \\
\text { tion schemes }\end{array}$ & $\bullet$ & $\bullet$ & $\bullet$ & $\bullet$ & $\bullet$ & $\bullet$ \\
\hline $\begin{array}{l}\text { Uses his/her prior } \\
\text { knowledge }\end{array}$ & $\bullet$ & $\bullet$ & $\bullet$ & $\bullet$ & $\bullet$ & $\bullet$ \\
\hline $\begin{array}{l}\text { Uses appropriate } \\
\text { terminlogy }\end{array}$ & & $\bullet$ & $\bullet$ & $\bullet$ & $\bullet$ & $\bullet$ \\
\hline Uses reasoning & & $\bullet$ & $\bullet$ & $\bullet$ & $\bullet$ & $\bullet$ \\
\hline $\begin{array}{l}\text { Uses 'if...then' } \\
\text { statements }\end{array}$ & $\bullet$ & $\bullet$ & & $\bullet$ & & $\bullet$ \\
\hline $\begin{array}{l}\text { Uses longer se- } \\
\text { quences of state- } \\
\text { ments }\end{array}$ & & $\bullet$ & & $\bullet$ & & $\bullet$ \\
\hline $\begin{array}{l}\text { Understands the } \\
\text { significance of de- } \\
\text { duction }\end{array}$ & & $\bullet$ & & & & $\bullet$ \\
\hline Uses formal proof & & $\bullet$ & & & & $\bullet$ \\
\hline
\end{tabular}

As we can see from the table of results, the students who achieved a strict proof (M2, M7, M8) were the students with a van Hiele level of 2, though they were assisted by the LVAR in the software environment, while student M1 used "if...then" statement using the LVAR.

The LVAR have thus helped elicit a constructional mode of thought from the pupil. Indeed, that LVAR play a significant role in developing pupil understanding and reasoning is clear from the fact that students demonstrated a shift from visual to formal proof during the experiment. The RVR led students to formulate "if ...then" propositions, thanks to the instrumental genesis evoked through the orchestration process. During the LVAR session, some students successfully entered the universe of their partner's thoughts and completed the task without pauses - and this under the undoubted stress of being observed by 20 other teachers--and are encouraged to construct a social scheme through the LVAR process and the semiotic mediation between teacher and student. The linking representations LVAR on multiple pages assisted them to react immediately and link their thoughts. Consequently through an inductive procedure they were led to a productive reasoning. All the time their interest was orientated to find the treasure, not only to solve the problem. So their responses included the subject matter.

\section{Summary of the findings of the research}

The core conclusions relate to the experimental group. The conclusions relating to the control group were reached through comparison with the experimental group and by means of tests.

The primary observation was how enthusiastically the students in the experimental group took part in static geometry activities after four weeks working on the software activities. 
The research presented in this paper was underlied by the characteristics of the theory of Realistic Mathematics Education (RME), initially formulated by Van Reeuwijk (1995) and briefly summarized by Drijvers (1999, p.35) namely the research concerned a "real (or realistic) world problem situation that students perceive as real or realistic" through which the students had the opportunity to develop:

b) "their own informal problem solving strategies"

c) "the two types of mathematization (mathematization) distinguishing between:

"the horizontal mathematization: modelling the problem situation into mathematics" and "the vertical mathematization: the process of reaching a higher level of abstraction".

d) "interaction among them and between students and the teacher,... because discussion and cooperation enhanced the reflection that is essential for the reinvention process."

e) "an integrated view of mathematics, as well as the flexibility to connect the different subdomains"

The results of the research can be illustrated in the following table: 


\section{Students of experimental group}

- During the activities structured a usage schema in order to use the tools while simultaneously organized their activity through the tool's own utilization schema.

- The transformation process had a significant impact for example: of the construction of the functional/operational process of rotation the student structured a utilization scheme of the tool, and consequently a mental image

- Formulated hidden "if... then" expressions

- The software helped the students overcome their obstacles and prove the specific cases of the problem.

- Irrespective of their van Hiele level, they made a correct shape, which proves they understood the meaning of "rotation of a segment".

- Students who explored the problem through dynamic representations proceeded to the proof, while the rest made worthy attempts by trying to reach conclusions using the mode of construction

- The students had operated and found the solution using a mental construction (or a series of recalled images). So the decision strategies adopted by the students in the experimental team during the software problem-solving process were conscious

- The LVAR spread over multiple pages helped the students to react instantaneously and to articulate their thoughts.

- The LVAR helped the students to operate in a auxiliary/ complementary manner, assimilating /accommodating their prior knowledge, or as a confirmation of the pupil's thought processes /mental approach.

- LVAR helped the students form rigorous Euclidean proofs

- The students were "starting to develop longer sequences of statements and beginning to understand the significance of deduction" (de Villiers, 2004).

- The students were forced to answer rapidly and spontaneously; the researcher kept her questions coming in a fast and continuous stream, which meant they did not have time to use paper and pencil. The researcher's classroom observations reveal that it was not always the same pupils who displayed the same spontaneous reflex reactions.

- They reached conclusions on the problem by correlating the theorems they already know

- Pre-existing knowledge of the theorems was very important to problem solving

An observation of their answers would indicate that the software has helped the students answer at a "higher level" than that indicated by the van Hiele test.

\section{The students in the control group}

- during the research with the static means did not successfully construct the shape

- did not understand the meaning of "rotating left/right by 90 degrees"

- made errors in the recognition of segments pupils considered equal

- No one achieved the proof, and their efforts were purely accidental. 


\section{Conclusions}

Representations were the first empirical mode leading to the proving process in Ancient Greece, too (see, for example, Socrates and Meno) although the process observed in Euclid's "Elements" does not display a transition from visual representation to rigorous reasoning. The visual representations can proof only specialized cases, while the Euclidean proof can empower every case by reinforcing the initial visual proof.

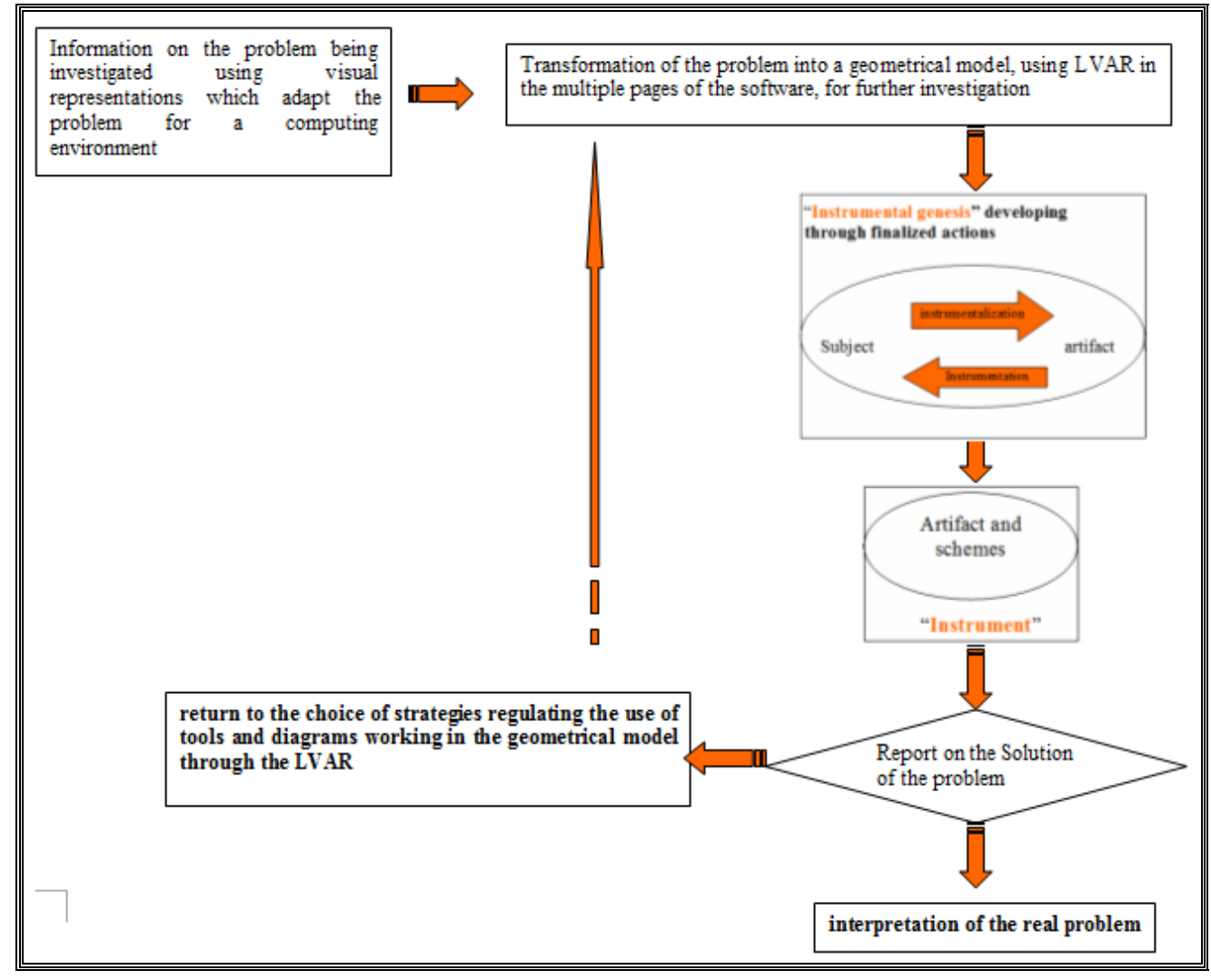

Diagram 1: interpretation of the problem solving in a dynamic geometry environment

Creating visual mathematical representation in the software can make it easier for students to grasp the relevant concepts by allowing the continuous manipulation of mathematical objects in real time. The LVAR are embedded into a multi-page file, and their active functions lead to the taking of decisions relating to solving the problem, while their construction can make Maths easier by being partly prepared by the teacher, which saves times. Like the different techniques the researcher used, the software tools can assist cognitive functions with a view to analyzing the data and composing the solution and make it easier for the student to reach decisions. Teachers can thus improve their students' knowledge by eliciting mental schemas from them, which is to say the students can be guided to reach conclusions which form a step-by-step visual proof. There are studies (for example Bennett \& Desforges, 1988) which caution that the problems used should be set in a familiar context and build on the students' extant knowledge. Analysis of the results of the presented in this paper research do indeed confirm that prior knowledge plays a significant role in solving the problem, as do teacher and software mediation. The pair's solutions during the experimental software process are limited to their familiar context, although they have solved the problem through LVAR using formal reasoning. The orchestrated experimental team solution included knowledge of theorems the pupils had understood, allowing us to form the hypothesis 
that the group might have employed other familiar theorems, which is indicative of the context's appropriateness for future research.

Jaime and Gutierrez (1995, p. 592) noted "the van Hiele model of mathematical reasoning has become a proved descriptor of the progress of students' reasoning in geometry and is a valid framework for the design of teaching sequences in school geometry". From the Van Hiele theory, it is clear that an understanding of formal reasoning can only develop at level 3, since that is where students start noticing the inter-relationships between the properties of a figure - something that didn't occur for the students in the control group. On the other hand, the researcher observed that before the software sessions, the students in the experimental team didn't differ from the students of the same level in the control group with regard to representations of problems and reasoning. According to Gawlick (2005, p.370): "The value of the dynamic approach is twofold: 1) it can be continued to higher levels and prepared on lower levels, so students get accustomed to the tools as well as to a 'discoverer's' habit of mind.2) on all levels, it provides a material base for the sequential phases of learning in van Hiele's description of progression from one level to another: namely they can explore the topic in a phase of directed orientation via DGS and then build the new concepts for themselves, drawing upon their previous knowledge."

The instrumental genesis procedure via the transformations undergone by the activity and the utilization schemes the students draw up with a view to solving the problem led to the construction of cognitive schemata which developed through collaboration and constant interaction with the environment. The instrumental genesis theory helped the researcher to interpret student behaviour in the dynamic geometry environment and to observe the relation between technical and conceptual components within instrumentation schemes. There were changes in the behaviour of the students (Guin \& Trouche, 1999, p.220) observed after their investigation in the dynamic geometry environment, taking into account their mathematical profile and the main features of the student's van Hiele level of geometrical thought claim.

Examining how the researcher addressed the research questions, we could say:

- Pre-existing knowledge of the theorems plays an important role in problem solving; although;

- The DGS environment helped the students to students to develop strategies for solving the problem;

- The van Hiele level derived from the students' answers is differed from their level in the pre-test;

- The students in the experimental group responded more correctly to the problem representation;

- The decision-making strategies employed by the students in the experimental team during the software problem-solving process were consciously adopted;

- The students in the experimental team alone could be induced to apply productive reasoning;

- LVAR contributed to the students constructing rigorous Euclidean proofs;

- LVAR process helped students to improve /develop their van Hiele levels.

The procedure described and analyzed allowed the researcher to reach conclusions relating to how students learn in a dynamic geometry environment with LVAR, which are comparable to a vibrant section in a textbook, and to how their level of reasoning develops-a phenomenon observed during the class sessions. Specifically, when students do not know how to go on, they return to a previous action, reconstructing the shape from scratch, for example, or undoing a given step which doesn't seem to have helped, trying in this way to get feedback with regard to a future procedure relating to solving the problem. The procedure in the dynamic geometry environment 
including LVAR this allows us to reach a semperasma (Patsiomitou \& Koleza, in press), as does Diagram 1, which depicts the problem-solution flow in a software environment, since the solution to the problem depends on the right decisions being made when the activity's strategies are being designed, on the right combination of LVAR, and on creating and choosing different interaction techniques.

Semperasma: a pupil can develop his/her level of knowledge by proceeding through increasingly complex, sophisticated and integrated figures and visualizations to a more complex linked representation of problem, and thereby moving instantaneously between two successive Linking Visual Active Representations only by means of mental consideration, without returning to previous representations to reorganize his/her thoughts.

\section{Acknowlegdements}

I would like to thank Professor Luc Trouche for his answers to my e-mails. I deeply appreciate the time he has dedicated to sharing his ideas, with regard to the schema of instrumental approach. Finally, I should like to thank the editor /translator Michael Eleftheriou, without which I could not have conveyed my thoughts in English with the requisite precision and clarity.

\section{References}

Almeqdadi, F. (2000). The effect of using the geometer's sketchpad (GSP) on Jordanian students' understanding of geometrical concepts. Jordon: Yarmouk University.

Artigue, M. (2000). Instrumentation issues and the integration of computer technologies into secondary mathematics teaching. Proceedings of the Annual Meeting of the GDM. Potsdam, 2000: Retrieved from: http://webdoc.sub.gwdg.de/ebook/e/gdm/2000

Bartolini Bussi, M., \& Mariotti, M. A. (1998). From drawing to construction: Teachers' mediation within the Cabri environment. In A. Olivier \& K. Newstead (Eds.), Proceedings of the 22nd Conference of the International Group for the Psychology of Mathematics Education (Vol. 3, pp. 247-254). Stellenbosh, South Africa.

Battista, M. T. (1998). Computer environments that engender students' construction of mathematical ideas and reasoning: A constructivist perspective. Paper presented at the NCTM Standards 2000 Conference.

Bellamy, R. K. E. (1996). Designing educational technology: Computer-mediated change. In B. A. Nardi (Ed.), Context and consciousness: Activity theory and human-computer interaction (pp. 123-146). (Cambridge, MA: The MIT Press).

Bennett, N., \& Desforges, C. (1988). Matching classroom tasks to students' attainments. Elementary School Journal, 88, $221-234$

Brousseau, G. (1986). Fondements et méthodes de la didactique des mathématiques. Recherche en Didactiques des Mathématiques, 7(2), 33-115.

Cerulli, Pedemonte, \& Robotti (2005). An integrated perspective to approach technology in mathematics education. Proceedings of the Fourth Congress of the European Society for Research in Mathematics Education (CERME 4), Sant Feliu de Guíxols, Spain, 17-21 February 2005, 1389-1399.

Cobb, P., \& Steffe, L. P. (1983). The constructivist researcher as teacher and model builder. Journal for Research in Mathematics Education, 14(2), 83-94. Retrieved from http://www.jstor.org/view/00218251/ap020063/02a00020/0

Cobb, P., Yackel, E., \& Wood, T. (1992). A constructivist alternative to the representational view of mind in mathematics education. Journal for Research in Mathematics Education, 23(1) 2-33.

Cohen, D. (1995). Crossroads in mathematics: Standards for introductory college mathematics before calculus. Memphis, TN: American Mathematical Association of Two-Year Colleges. 
De Villiers, M. (1998). An alternative approach to proof in dynamic geometry. In R. Lehrer * D. Chazan, Designing Learning Environments for Developing Understanding of Geometry and Space (pp. 369393). Hillsdale, N.J: Lawrence Erlbaum Associates.

De Villiers, M. (1999). Mathematical treasure hunting. KZN Math Journal, 4(2), Nov, 23-28 and Proceedings of AMESA 2000, Univ. Free State, 271-276. Retrieved from http://mzone.mweb.co.za/residents/profmd/homepage.html

De Villiers, M. (2004). Using dynamic geometry to expand mathematics teachers' understanding of proof. International Journal of Mathematical Education in Science and Technology, 35(5), 703-724.

Discussion session of the Mind \& Machine Group: Report. (2003). Coordinator Paul Drijvers, CAME Meeting 2003, Reims (France). Available at http://www.lkl.ac.uk/research/came/events/reims/Theme2Group-Summary.doc

Dixon, J. (1996). English language proficiency and spatial visualization in middle school students' construction of the concepts of reflection and rotation using the GSP. Dissertation Abstract International, DAI-A 56111, University of Florida.

Drijvers, P. H. M. (1999). Students encountering obstacles using CAS: A developmental-research pilot study. In P. Kent, J. Monaghan, \& N. Zehavi (Eds.), Papers (Presentations, Reactions and Keynotes) of the CAME (Computer Algebra in Mathematics Education) meeting at the Weizmann Institute of Science, Rehovot,Israel, August 1-2, 1999 (pp. 34-49). Available online from http://metric.ma.ic.ac.uk/came/events/weizmann

Drijvers, P.H.M. (2003). Learning algebra in a computer algebra environment. Design research on the understanding of the concept of parameter, Dissertation. Utrecht: CD-press.Retrieved from www.fi.uu.nl/ pauld/dissertation

Duval, R. (1991). Structure du raisonnement deductif et apprentissage de la démonstration. Educational Studies in Mathematics, 22, 233-261.

Duval, R. (1993). Registres de représentation sémiotique et functionnement cognitif de la pensée. Annales de Didactique et de Sciences Cognitives, 5, 37-65.

Edwards, L. (2005). Gesture and mathematical talk: Remembering and problem solving. Paper presented at American Educational Research Association Annual Meeting, Montreal, Canada

Eisenberg, T, \& Dreyfus T. (1990) On the reluctance to visualize in mathematics. In W. Zimmermann \& S. Cunninham (Eds.), Visualization in Teaching and Mathematics. MAA Series, USA.

FitzSimons, G. E. (2005). Technology mediated post-compulsory mathematics: An activity theory approach. International Journal of Mathematical Education for Science and Technology, 36(7), 769-777.

Freudenthal, H. (1971). Geometry between the devil and the deep sea. Educational Studies in Mathematics, 3(3-4), 413-435. Retrieved from http://www.springerlink.com/content/t43797147n37r585/fulltext.pdf

Freudenthal, H. (1973). Mathematics as an educational task. Dordrecht: Reidel.

Fuys, D., Geddes, D., \& Tischler, R. (Eds). (1984). English translation of selected writings of Dina van Hiele-Geldof and Pierre M. van Hiele. Brooklyn: Brooklyn College. (ERIC Document Reproduction Service No. ED 287 697).

Fuys, D., Geddes, D., \& Tischler, R. (1988). The van Hiele model of thinking in geometry among adolescents. Va. National Council of teachers of Mathematics, Reston.

Gamow, G. (1988). One, two, three--infinity. New York: Dover Publications. (Original work published 1947)

Gawlick, T. (2005). Connecting arguments to actions -Dynamic geometry as means for the attainment of higher van Hiele levels. Zentralblatt für Didaktik der Mathematik, 37(5), 361-370. 
Goldenberg, E. P. (1995). Ruminations about dynamic imagery (and a strong plea for research). In R.Sutherland \& J. Mason (Eds.), Exploiting mental imagery with computers in mathematics education (pp.202-224). Berlin: Springer-Verlag.

Goldenberg, E. P. (1999), Principles, art, and craft in curriculum design: The case of connected geometry. International Journal of Computers for Mathematical Learning, 4. Kluwer.

Goldin, G., \& Janvier, C. (1998). Representation and the psychology of mathematics education. Journal of Mathematics Behaviour, 17(1), 1-4.

Growman, M. (1996). Integrating Geometer's sketchpad into a geometry course for secondary education mathematics majors. Association of Small Computer users in Education (ASCUE) Summer Conference Proceedings, 29th, North Myrtle Beach, SC

Guin, D., Ruthven, K., \& Trouche, L. (2004). Conclusion: The didactical challenge of symbolic calculators: turning a computational device into a mathematical instrument. Mathematics Education Library (Vol. 36). New York: Springer. Available from http://www.springerlink.com

Guin, D., \& Trouche, L. (1999). The complex process of converting tools into mathematical instruments: The case of calculators. International Journal of Computers for Mathematical Learning, 3(3), 195-227.

Guin, D., \& Trouche, L. (2002). Mastering by the teacher of the instrumental genesis in CAS environments: Necessity of instrumental orchestrations. Zentralblatt für Didaktik der Mathematik, 34(5), 204211. Available on line from http://www.subs.emis.de/journals/ZDM/zdm025a4.pdf

Hanna, G. (1998). Proof as understanding in geometry. Focus on learning problems in mathematics, $20(2 \& 3), 4-13$.

Hanna, G. (2000). A critical examination of three factors in the decline of proof. Interchange, 31(1), 21-33.

Harel, G., \& Sowder, L. (1996). Classifying processes of proving. In L. Puig \& A. Gutierrez (Eds.), Proceedings of the 20th Conference of the International Group for the Psychology of MathematicalEducation (Vol. 3, pp. 59-66). Valencia, Spain.

Hoffer, A. (1983). van Hiele-Based Research. In R. Lesh \& M. Landau (Eds.), Acquisition of mathematics concepts and processes. Orlando, FL: Academic Press.

Jackiw, N. (1988). The Geometer's Sketchpad [Computer Software].Berkeley, CA: Key Curriculum Press

Jahn, A. P. (2002). "Locus" and "Trace" in Cabrigéomètre: Relationships between geometric and functional aspects in a study of transformations. ZDM, 34 (3).

Jaime, A., \& Gutierrez, A. (1995). Guidelines for teaching plane isometries in secondary school. The Mathematics Teacher, 88(7), 591-597.

Janvier, C. (1987). Representation and understanding: The notion of function as an example. In C. Janvier (Ed.), Problems of Representations in the Teaching and Learning of Mathematics (pp. 19-26). Lawrence Erlbaum Associates.

Jones, K. (2000). Providing a foundation for deductive reasoning: Students' interpretations when using dynamic geometry software and their evolving mathematical explanations. Educational Studies in Mathematics, 44(1-2), 55-85. Retrieved from http://eprints.soton.ac.uk/9809

Kaput, J. J. (1989). Linking representations in the symbol systems of algebra. In S. Wagner \& C. Kieran, Research issues in the learning and teaching of algebra (pp. 167-194). Hillsdale, NJ: Erlbaum

Kaput, J. J. (1994). The representational roles of technology in connecting mathematics with authentic experience. In R. Biehler, R.W. Scholz, R. Strässer, \& B. Winkelmann (Eds.), Didactics of mathematics as a scientific discipline. Kluwer Academic Publishers.

Kaput, J. J. (1998). Representations, inscriptions, descriptions and learning: A kaleidoscope of windows. The Journal of Mathematical Behavior, 17(2), 265-281.

Kaput, J. J., Noss, R., \& Hoyles, C. (2002). Developing new notations for a learnable mathematics in the computational area. In L. D. English (Ed.), Handbook of international research in mathematics educa- 
tion (pp. 51-75). Mahwah, NJ: Lawrence Erlbaum Associates. Available online from: http://www.lk1.ac.uk/rnoss/papers/DevelopingNewNotations.pdf

Kemmis, S., \& McTaggart, R. (1982). The action research planner. Victoria, Australia: Deakin University Press

Kieran, C., \& Dreyfus, T. (1998). Collaborative versus individual problem solving: Entering another's universe of thought. In A. Olivier \& K. Newstead (Eds.), Proceedings of the 22nd Conference of the International Group for the Psychology of Mathematics Education, Vol. 3. (pp. 112-119). Stellenbosch, South Africa: University of Stellenbosch.

Kilpatrick, J. (1987). Problem formulating: Where do good problems come from? In A Schoenfeld, Cognitive science and mathematics education. Hillsdale, NJ: Lawrence Erlbaum Associates

Kuutti, K. (1996). Activity theory as a potential framework for human computer interaction research. In B. A. Nardi (Ed.), Context and consciousness: Activity Theory and Human-Computer Interaction (pp. 1746). Cambridge, MA: The MIT Press.

Laborde, C. (1993). The computer as part of the learning environment: The case of geometry. In C. Keitel $\&$ K. Ruthven (Eds.), Learning from computers: Mathematics education and technology (pp. 48-67). Berlin: Springer-Verlag.

Laborde C. (1999). Vers un usage banalise de Cabri-Geometrie en classe de seconde: Analyse des facteurs de l'integration, Calculatrices symboliques et geometriques dans l'enseignement des mathematiques, Actes du colloque francophone europıen (pp. 79-94).Montpellier: IREM, Universite Montpellier II.

Laborde, C. (2005). The hidden role of diagrams in students' construction of meaning in geometry. In J. Kilpatrick, C. Hoyles, O. Shovsmose \& P. Valero (Eds.), Meaning in mathematics education (pp. 159179). New York: Springer.

Laborde, J-M., Baulac, Y., \& Bellemain, F. (1988) Cabri Géomètre [Software]. Grenoble, France: IMAGCNRS, Universite Joseph Fourier.

Larew, L. W. (1999). The effects of learning geometry using a computer-generated automatic draw tool on the levels of reasoning of college developmental students. Unpublished Doctoral dissertation, West Virginia University

Lejeune, A., \& Pernin, J-P. (2004). A taxonomy for scenario-based engineering. Cognition and Exploratory Learning in Digital Age Proceedings, p.249-256, Lisboa, Portugal.

Mariotti, M. A. (2002). Influences of technological advances in students' mathematical learning. In L. D. English (Ed.), Handbook of international research in mathematics education (ch. 27, pp. 695-723). Mahwah, New Jersey: Lawrence Erlbaum Associates. Available on line from http://telma.noekaleidoscope.org/outcomes/papers

Nardi, B.:1996, Studying context: A comparison of activity theory, situated action models and distributed cognition. In B.A. Nardi (Ed). Context and consciousness: Activity theory and human computer interaction, (pp 35-52). Cambridge, MA: MIT Press.

Noss, R., \& Hoyles, C. (1996). Windows on mathematical meanings: Learning cultures and computers. Dordrecht: Kluwer

Olivero, F. (1999). Cabri-géomètre as a mediator in the process of transition to proofs in open geometric situations. In W. Maull \& J. Sharp (Eds.), Proceedings of the 4th International Conference on Technology in Mathematics Teaching (CD-ROM). Plymouth, UK

Olivero, F. (2002). The proving process within a dynamic geometry environment. $\mathrm{PhD}$ thesis, Bristol, UK : University of Bristol, Graduate School of Education.

Olivero, F., \& Robutti, O. (2007) Measuring in dynamic geometry environments as a tool for conjecturing and proving. International Journal of Computers for Mathematical Learning, 12(2).

Papert, S. (1980). Mindstorms. Children, computers and basic ideas. New York: Basic Books. 
Patsiomitou, S., \& Koleza, E. (in press). The development of geometrical thinking through linking visual active representations. Proceedings of the $5^{\text {th }}$ International Colloquium on the Didactics of Mathematics. University of Crete, Department of Education.

Pea, R. (1985). Beyond amplification: Using the computer to reorganize mental functioning. Paper presented at the AERA - Computers as tools of the intellect: Lessons from the past and an agenda for the future, Chicago, IL.

Presmeg, N. (1986). Visualisation and mathematical giftedness. Educational Studies in Mathematics 17, 297-311.

Rabardel, P. (1995). Les hommes et les technologies, approche cognitive des instruments contemporains. Paris : Armand Colin.

Roschelle, J. M., Pea, R. D., Hoadley, C. M., Gordin, D. N., \& Means, B. M. (2000). Changing how and what children learn in school with computer-based technologies. Children and Computer Technology, 10(2). Retrieved from http://www.futureofchildren.org/usr_doc/vol10no2Art4.pdf

Scher, D. (2003). Dynamic visualization and proof: A new approach to a classic problem. The Mathematics Teacher, 96(6), 394.

Schwartz, J., \& Yerushalmy, M. (1992). Getting students to function in and with algebra. In G. Harel \& E. Dubinsky (Eds.), The concept of function. Aspects of epistemology and pedagogy (Vol. 25, pp. 261289).

Sedig, K., Klawe, M., \& Westrom, M. (2001). Role of interface manipulation style and scaffolding on cognition and concept learning in learnware. ACM Transactions on Computer-Human Interaction, 8(1), $34-59$.

Sedig, K., Rowhani, S., \& Liang, H. (2005). Designing interfaces that support formation of cognitive maps of transitional processes: An empirical study. Interacting with computers, 17(4), 419-452. Elsevier Science. Retrieved from http://www.elsevier.com

Sedig, K., \& Sumner, M. (2006). Characterizing interaction with visual mathematical representations. International Journal of Computers for Mathematical Learning, 11, 1-55. New York: Springer.

Straesser, R. (2002). Research on dynamic geometry software (DGS) - An introduction. ZDM, 34(3), 65.

Trouche, L. (2004). Managing the complexity of the human/machine interaction in computerized learning environments: Guiding students' command process through instrumental orchestrations. International Journal of Computers for Mathematical Learning 9, 281-307. Kluwer Academic Publishers.

Trouche, L. (2006). An Instrumental, Didactical and Ecological Approach (IDEA) to the process involved in learning mathematics... and some consequences for reconsidering the teaching of Mathematics. Center for Naturfagenes Didaktik, Copenhague.

Usiskin, Z. (1982). Van Hiele levels and achievement in secondary school geometry. Chicago, IL: University of Chicago.

van Hiele, P. M. (1986). Structure and insight: A theory of mathematics education. Orlando, Florida: Academic Press.

Van Reeuwijk, M. (1995). Students' knowledge of algebra. In: Proceedings of the $19^{\text {th }}$ International Conference for the Psychology of Mathematics Education. pp. 135-160

Verillon, P. \& Rabardel, P. (1995) Cognition and artefacts: A contribution to the study of thought in relation to instrumented activity. European Journal of Psychology of Education, 10(1), 77-101.

Vergnaud G. (1987) Conclusion. In Problems of Representations in the Teaching and Learningof Mathematics (Janvier C. Editor) Lawrence Erlbaum Associates, pp. 227-232.

Vygotsky, L.S. (1934/1962). Thought and language. MIT Press

Waern Y. (2003) Editorial from Computer Artefact to Instrument for Mediated Activity. Interacting with Computers, Elsevier, Volume 15, Number 6, December 2003, pp. 731-735(5) 
Yousef, A. (1997) The Effect of the GSP on the Attitude toward Geometry of High School Students. Dissertation Abstract International, A 58105, Ohio University.

\section{Biography}

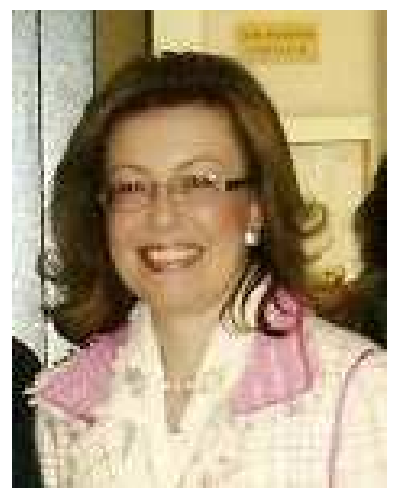

Stavroula Patsiomitou is a mathematician working in the state Secondary Education. She was awarded her Masters degree in Education and specifically in the Didactics and Methodology of Mathematics of the Inter -university programm of University of Athens (NKUA) and University of Cyprus in 2005. Entitled "Fractals as a framework for comprehending sequences and limits through the meaning of area in an environment based on the dynamic manipulation of mathematical objects", her Master's thesis employed the Geometer's Sketchpad v.4 dynamic geometry software package. An excerpt of her Master thesis has been published in summarized form in the Proceedings of the International Conference of Technology in Mathematics Education ICTMT8 (2007).

Recently, she was involved in the Greek translation of the software, advising the translation team on the suggestion of its Chief Technology Officer, Nicholas Jackiw. Her name is included on the splash screen "Special Thanks to ..." of the Greek version of the Geometer's Sketchpad v.4 dynamic geometry software.

She has written an algebra textbook for 16-18 year-olds, written and presented twentytwo papers at conferences in Greece and a further three abroad, and written numerous articles for the journals of the Hellenic Mathematical Society. Her research interests centre on computer assisted mathematics learning and teaching in general, and on Dynamic Geometry software in particular.

She is currently working on her Ph.D thesis at University of Ioannina, under the supervision of Eugenia Koleza, Professor of Mathematics Education entitled "Developing students' geometrical thinking through transformational processes and through interaction techniques in a computing environment". 